\title{
The phylogenetic position of the extinct arachnid order Phalangiotarbida Haase, 1890, with reference to the fauna from the Writhlington Geological Nature Reserve (Somerset, UK)
}

\author{
Jessica R. Pollitt, Simon J. Braddy and Jason A. Dunlop
}

\begin{abstract}
Study of abundant phalangiotarbid (Arachnida: Phalangiotarbida) material provisionally assigned here to Bornatarbus mayasii (Haupt in Nindel 1955)-from the Upper Carboniferous of Writhlington, UK, has revealed new information about some previously equivocal characters. The present authors report a trifurcate apotele, possible spiracles on sternite 5, and confirm the presence of 10 opisthosomal tergites plus a dorsal anal operculum. The affinities of phalangiotarbids are obscure, with most authors favouring affinities with Opiliones (harvestmen) and/or Acari (mites and ticks). Phalangiotarbida is scored for characters used in previous studies of arachnid relationships. A cladistic analysis based on 63 characters using 13 terminal arachnid taxa (plus a hypothetical outgroup), resolves Phalangiotarbida as sister group to (Palpigradi+ Tetrapulmonata): the taxon Megoperculata sensu Shultz (1990). Even under cladistic analysis, the position of the Phalangiotarbida remains hard to resolve, but a prosomal sternite with distinct sclerites potentially groups them with the Megoperculata.
\end{abstract}

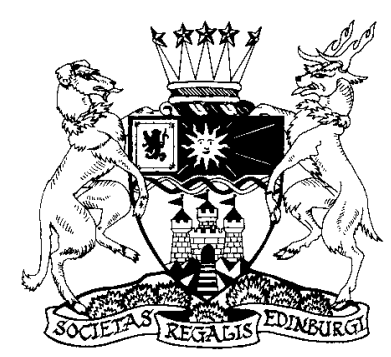

KEY WORDS: Arthropod, Chelicerata, cladistics, morphology, Upper Carboniferous.

The extinct arachnid order Phalangiotarbida is an enigmatic taxon that can, nevertheless, be a significant component of Coal Measures arthropod faunas. Originally thought to be restricted to the Westphalian A-D of the Upper Carboniferous, specimens have recently been found in the Lower Devonian (Poschmann \& Jansen 2002), Lower Carboniferous (Rößler \& Schneider 1997) and extend through to the early Permian (Rößler et al. 2003). The aims of the present study are: (1) to investigate some previously equivocal characters and their palaeobiological significance based on the rich Writhlington material; and (2) to assign this material taxonomically and try to resolve the phylogenetic position of Phalangiotarbida within the Arachnida.

There have been numerous investigations of arachnid phylogeny (e.g. see Giribet et al. 2002 and references therein). Many previous studies have not scored characters based on fossil taxa. However, one extinct arachnid order, the spider-like Trigonotarbida, has been incorporated into earlier cladistic analyses (Shear et al. 1987; Dunlop 1996c; Giribet et al. 2002). Excellent preservation of trigonotarbids from the Devonian Rhynie Chert of Scotland (Hirst 1923) and Gilboa, New York State, USA, (Shear et al. 1987) has permitted relatively complete coding for characters relating to cuticular morphology. Phalangiotarbids have been incorporated into only one previous cladistic analysis (Beall \& Labandeira 1990). The dataset used in this analysis was not published and no supporting apomorphies were given for their [Phalangiotarbida (Opiliones + Acari)] hypothesis.

The Writhlington Geological Nature Reserve site (WGNR), in Somerset, UK has yielded around 80 phalangiotarbid fossils, and thus is second only to the Mazon Creek region in terms of abundance (Beall 1991) (see Fig. 1 for geographical location). Unlike the more diverse Mazon Creek fauna, the
Writhlington material seems to represent a single species (see Section 6). Some of these Writhlington fossils have been previously examined (Beall 1984, 1985, 1991), but many have not and these form the basis of the present detailed morphological study.

\section{Geological setting and preservation}

Coal-bearing deposits of Upper Carboniferous age occupy a synclinal basin around Radstock, in Somerset, UK (Jarzembowski 1989). The village of Writhlington lies in the eastern part of this basin. A mine, sunk in its valley bottom, was closed in 1960 and the area was made into a Nature Reserve (WGNR; [ST 703 553]). Arthropod finds suggest that the fossil material is from the roof of the number 10 coal seam (see Fig. 2 for stratigraphic section). A trigonotarbid and some xiphosuran fossils have been described from the laterally equivalent number 9 seam at Kilmerston (Ambrose \& Romano 1972). The Writhlington deposit has been dated to Westphalian D; e.g. see Jarzembowski 1989 for further detail).

The best-known phalangiotarbid faunas (e.g. Mazon Creek and Coseley) preserve the fossils in ironstone concretions. By contrast, the Writhlington fossils are preserved as compressions on bedding plane surfaces. Most of the phalangiotarbid specimens from Writhlington are preserved as external moulds, and dorsal features are often preserved on both the part and counterpart.

\section{Material and methods}

All phalangiotarbid specimens in the collections of the Bristol City Museum and Art Gallery (BRSMG) were examined 


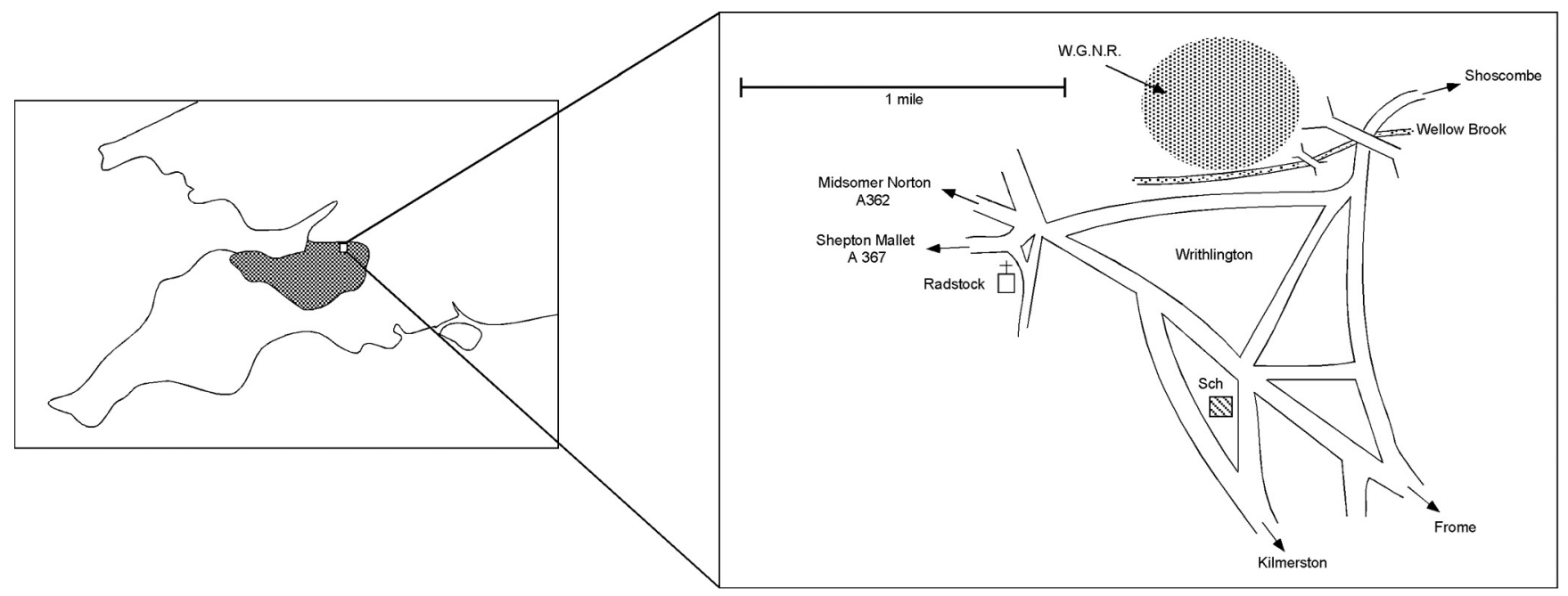

Figure 1 Geographical location of the Writhlington Geological Nature Reserve in Somerset, UK (strictly speaking, Writhlington is now located in the county of Bath and North East Somerset).

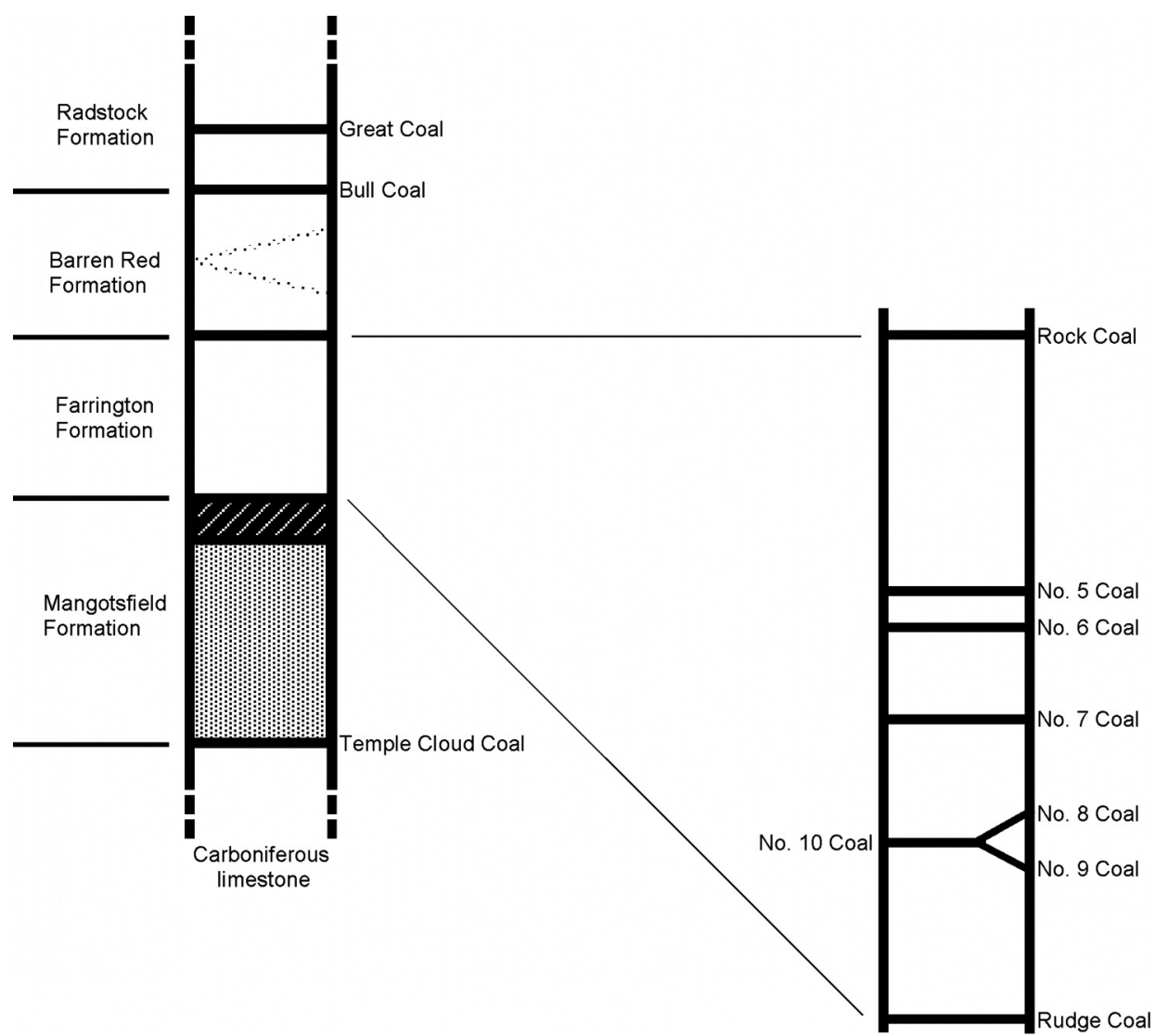

Figure 2 Stratigraphical section through some of the Somerset Coalfield, with a magnified representation of the Farrington Formation showing the coal seams (adapted from Thomas \& Cleal, 1994, fig. 1).

(accession numbers Cd5259-98). The specimens of Mesotarbus peteri Dunlop \& Horrocks, 1997 were restudied from their repository in the Manchester Museum (MM; accession numbers LL11149-52). Latex peels of some Mazon Creek phalangiotarbids were provided by $\operatorname{Dr}$ P. A. Selden. All specimens were studied with a binocular microscope and drawings were prepared with the aid of a camera lucida. All specimens were studied both dry and immersed under $70 \%$ alcohol to enhance the distinction between the fossil and the surrounding matrix. Photographs of whole specimens were taken under polarised light. Photographs of specific structures were taken either dry or under alcohol (see figure captions for details).
All measurements are given in millimetres. Tubercle density, tubercle size and carapace length were measured using methods discussed in Selden (1992). The morphological terminology of Petrunkevitch (1955) is followed throughout the present study unless stated otherwise. Descriptions and interpretations are based on a composite of Writhlington material (Figs 3-5), unless otherwise stated, and individual specimens are referred to by accession number. Comparative details from Mesotarbus peteri from the Upper Carboniferous of Lancashire are commonly referred to in the text. Most features, except where specified, are described as they would have appeared in life. A reconstruction of the Writhlington form is presented in Figure 6. 


\subsection{Cladistic analysis}

For the phylogenetic analysis, an original dataset was analysed: new character states derived from the Writhlington phalangiotarbids were incorporated into a dataset composed of characters (Table 1) taken mostly from Shultz (1990), Dunlop (1996c), Wheeler \& Hayashi (1998) and Giribet et al. (2002). Scorings and polarities from these papers are used here unless stated otherwise, and for the first time, these characters are scored - where possible - for Phalangiotarbida. Full descriptions of all characters are provided in these original papers. However, several alterations were made and these are discussed in detail in Section 5.2.

The dataset analysed in this study has 63 morphological characters and 13 terminal taxa: the extant arachnid orders Palpigradi, Araneae, Amblypygi, Thelyphonida, Schizomida, Ricinulei, Acari, Opiliones, Scorpiones, Pseudoscorpiones and Solifugae, and the extinct arachnid orders Phalangiotarbida and Trigonotarbida. A hypothetical outgroup, labelled 'Ancestor', expressing plesiomorphic states, was included in the dataset to root the cladogram. The outgroup comparisons included the Euypterida, Xiphosura, Pantopoda, Trilobita and early derivative Crustacea, as in Shultz (1990), or as otherwise stated in the papers referenced in Section 5.2. The dataset in Table 1 was entered into the PAUP computer program (Version 4.0b10*, Swofford 2002) in NEXUS format. A dash (-) indicates inapplicable characters and a question mark (?) indicates missing data (unknown character state). All characters were unordered (i.e. any character can transform to any other state at equal cost) and equally weighted.

Initially, the dataset was tested for a significant cladistic signal using the permutation tail probability (PTP) test (1000 replicates with heuristic search via 10 random stepwise additions) (Faith \& Cranston 1991). The null hypothesis of this test is that 'the analysis of a comparable set of randomly covarying characters could produce a cladogram of equal, or even shorter, length' (Kitching et al. 1998). The null hypothesis can be rejected if the $P$-value is less than 0.05 .

A phylogenetic analysis of the dataset in Table 1 was conducted. Because of the small size of the dataset, the branch-and-bound search method could be executed. Character states were reconstructed using the 'accelerated transformation optimisation' (ACCTRAN) criterion. This option always assigns the maximum amount of change for each branch, and therefore, maximises homoplastic character changes which are represented as reversals, rather than as parallelisms (Pinna 1991). Consequently, primary homologies are preserved as long as possible within the constraints of parsimony.

Bootstrap proportions (1000 replicates with heuristic search via random stepwise addition) (Felsenstein 1985) were calculated to measure the frequency of a branch's occurrence in the resampling of pseudoreplicates from the dataset (and thus, its strength of support).

Branch support values (Bremer 1994) were performed and calculated in PAUP. This provides a measure of relative support for each clade since it calculates the number of additional steps which are required before the most parsimonious tree (MPT) topology starts to break down.

The ensemble consistency index (CI; Kluge \& Farris 1969) in PAUP was used to examine the relationship between the entire dataset and a particular tree topology, and hence, measures the level of homoplasy in the dataset. The ensemble retention index (RI; Farris 1989) measured support for the trees based on the similarity caused by synapomorphy only. Uninformative characters were excluded from the analyses since these can affect both the CI and RI (Smith 1994).
Finally, the full dataset from Table 1 was entered into the MacClade Version 3.1 computer program (Maddison \& Maddison 1997) and the evolution of the 64 characters was traced onto the minimal-length topology specified by PAUP (Swofford 2002).

\section{Morphology of the Writhlington material}

\subsection{Carapace}

The carapace is semicircular in outline. Some specimens (e.g. Cd5270A; Fig. 3g, h) display curved lateral margins, and fairly straight anterior and posterior borders whilst others (e.g. Cd5286A; Fig. 3a) possess straighter lateral margins, and more curved transverse anterior and posterior borders. The former were thought to correspond to Phalangiotarbus Haase, 1890 and the latter to Leptotarbus Petrunkevitch, 1945 (e.g. Beall 1991). However, studies have shown that these two genera are synonymous and that their different appearance is a result of distortion of the fossils; the Writhlington material is typically skewed from its original bilateral symmetry (Beall 1991; Fitton 2002).

The carapace is fairly dorso-ventrally convex and would not have been especially flat in life. A single, prominent, median ocular tubercle is present, close to the anterior border of the carapace, upon which there are three pairs of eyes (Fig. 3b; see also Section 3.2).

All carapaces studied bear three marked, narrow, symmetrical grooves on either side of the eye tubercle (Fig. 3g, h). Compression of the exoskeleton during preservation can result in artificial folds in some arachnid fossils (Dunlop 1996a; Dunlop \& Horrocks 1996). However, the symmetry and occurrence of these carapace grooves on each phalangiotarbid specimen indicate that they are not taphonomic in origin. The external surface of the carapace in arachnids often reflects the arrangement of the underlying musculature, and these ridges probably represent muscle attachment sites (cf. Shultz 1999).

Fine tuberculation can be seen on the carapace surface. The carapace is surrounded by a narrow marginal rim that is folded ventrally (Cd5287B; Fig. 3c) and pitted in a regular fashion, representing a continuation of the carapace tubercles. There is no obvious function of this rim, but it is similar to the doublure seen in some Amblypygi (Shultz 1999).

\subsection{Eyes}

The Writhlington material has six eyes located on a median ocular tubercle (Fig. 3a, b). Arachnids typically express a combination of median and/or lateral eyes, the latter derived from multifaceted compound eyes like those of xiphosurans. The phalangiotarbid eyes form a discrete group and all six lenses are of a similar size. Thus, it is difficult to resolve whether the eye tubercle includes median and lateral eyes, or lateral eyes only. All three pairs of eyes seem to be evenly positioned on the lateral sides of the eye tubercle, and therefore, the latter arrangement (i.e. three pairs of lateral eyes) is tentatively accepted. Further details of lens structure are lacking.

\subsection{Mouthparts}

No chelicerae or pedipalps are seen preserved in the Writhlington material. The phalangiotarbid Mesotarbus peteri shows two very small grooves which are likely to be impressions of the tiny chelicerae on one specimen (MM LL 11151; Dunlop \& Horrocks, 1997, figs 5a, 6a). Unfortunately, details of cheliceral morphology (number of articles, chelate or clasp-knife?) 

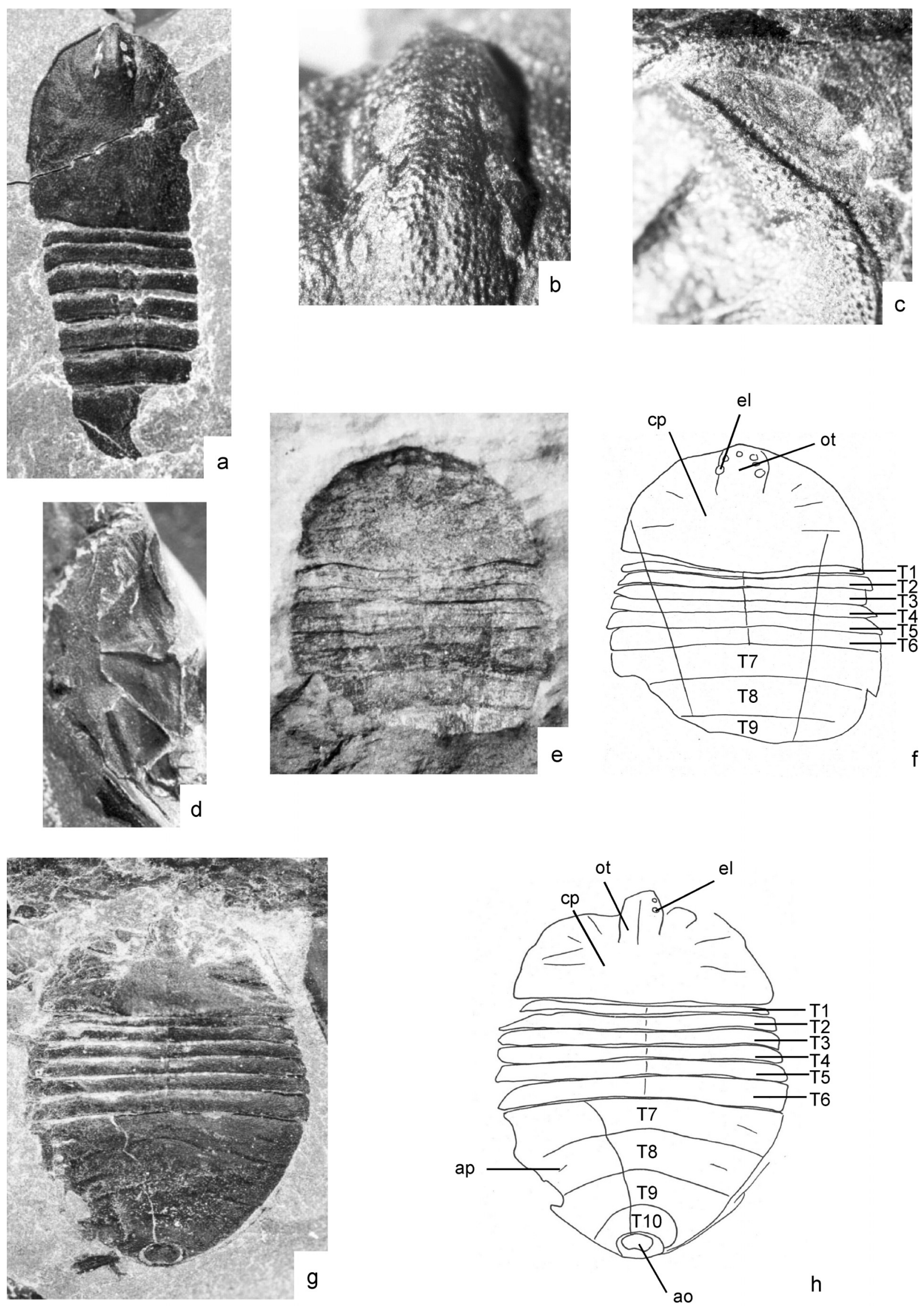

Figure 3 Bornatarbus mayasii (Haupt in Nindel, 1955): (a) Cd5286A, part, whole specimen, dorsal view; $\times 4 \cdot 8$. Taken under polarising light; (b) Detail of Cd5286A, showing ocular tubercle displaying six eye lenses; $\times 24 \cdot 8$; (c) Cd5287B, internal mould of the carapace showing the narrow marginal rim; $\times 22 \cdot 1$. Immersed in alcohol; (d) Cd5302A, counterpart, three unarticulated coxae; $\times 3 \cdot 9$; (e) Cd5279, whole specimen, dorsal view of juvenile; $\times 7 \cdot 2$. Immersed in alcohol; (f) Camera lucida drawing of same specimen; (g) Cd5270A, part, whole specimen, dorsal view showing posterior opisthosomal segmentation, apodemes and dorsal anal operculum; $\times 3 \cdot 7$. Taken under polarising light; (h) Camera lucida drawing of same specimen. Abbreviations: (ao) anal operculum; (ap) apodeme; (cp) carapace; (el) eye lens; (ot) ocular tubercle; and (T1-10), tergites 1 to 10. 
remain equivocal (but see Section 5.2.2), and this is one of the main hindrances to resolving the position of phalangiotarbids.

\subsection{Coxo-sternal region}

The sternum is not preserved in any Writhlington material, but is known in, for example, the neotype of Phalangiotarbus subovalis (Woodward, 1872) (see Dunlop \& Horrocks 1997, figs 1,2) and other taxa in the literature (summarised in Petrunkevitch 1955). In P. subovalis it is composed of five sclerites in three rows with a 1-2-2 arrangement; some other taxa where the sternum is known express a 1-2-1 arrangement.

No pedipalpal coxae can be seen in the Writhlington material. An example of some leg coxae, preserved in spatial relationships to each other, is found (Cd5302A; Fig. 3d). There are no structures preserved nearby which can offer information as to the orientation or position of these coxae. However, one Writhlington specimen (Cd5262A and B) has the coxae of walking legs 3 and 4 actually preserved in place (Figs 4a, b, 5a, b). They are huge compared with the relative size of the same coxae of some other fossil arachnids, (e.g. the extinct Haptopoda; Dunlop 1999). Based on the neotype of Phalangiotarbus subovalis (see Dunlop \& Horrocks 1997, figs 1, 2), it is suggested here that the first three leg coxae (1-3) abut the sternum while the last coxa (4) attaches behind it, as, for example, in trigonotarbids and the haptopodid species. All phalangiotarbid leg coxae lack gnathobases, endites or tuberculation, and thus, these leg coxae are unlikely to have played a role in feeding.

\subsection{Walking legs}

Articulated or disarticulated walking legs are preserved in only two Writhlington specimens (Cd5262A and B; Cd5273A and B). One of the specimens (Cd5262A and B; Figs 4a, b, 5a, b) shows the trochanter of leg 3. The other specimen (Cd5273 A and B; Fig. 5c-e) shows a disarticulated apotele (in close proximity to a phalangiotarbid body) with a trace of the preceding telotarsus (or tarsus in more general arachnid terminology). The apotele is roughly $1 \mathrm{~mm}$ wide, trifurcate in shape and clearly has three elements that are all approximately of equal length (c. $1 \mathrm{~mm}$ ). All the elements appear adjacent to one another and the lateral elements do not seem to insert on the central one (Fig. 5c-e). From its position relative to the body, this apotele is likely to belong to walking leg 4 on the right side. Apoteles in previous reconstructions of Phalangiotarbida have always been hypothetical (e.g. Beall 1991; Dunlop \& Horrocks 1997). Dunlop \& Horrocks (1997) based their reconstruction of phalangiotarbid apoteles upon those of wellpreserved Devonian Trigonotarbida (Shear et al. 1987).

Since the order Phalangiotarbida does not possess a modified leg 1, it seems reasonable to suppose that it has an apotele on all walking legs similar to that preserved here. Mesotarbus peteri implies that the walking legs increase slightly in length posteriorly and display a typical arachnid podomere pattern of: coxa, trochanter, femur, patella, tibia, basitarsus and telotarsus. The femora are undivided (Dunlop \& Horrocks 1997). All podomeres show a groove running along at least the dorsal surface.

\subsection{Opisthosoma}

A broad junction is present between the prosoma and opisthosoma (Fig. 3g, h). A narrow pedicel could be concealed from view and could superficially appear to be a broad juncture, as is the case for Ricinulei (Petrunkevitch 1949). Therefore, care must be taken when identifying the juncture type. Superimposition of drawings of dorsal and ventral surfaces taken from Dunlop \& Horrocks (1997) shows that the first visible tergite is undoubtedly the first true tergite. Some specimens have the carapace slightly displaced from the anterior opisthosomal border, hence revealing that there are no hidden tergites under the carapace or reduced tergites, as in the so-called 'locking ridge' of Trigonotarbida (Dunlop 1996c).

The opisthosomal segmentation of phalangiotarbids has proved controversial. Previous hypotheses are summarized as follows: (1) Pocock (1911, p. 45) considered that the 'terga of the opisthosoma were only eight or nine in number', but the 'sterna were apparently only seven in number'. Dunlop \& Horrocks (1997, p. 374) suggested that Pocock misinterpreted three sternites as tergites because 'in compression the division into sternites is often superimposed dorsally'; (2) Petrunkevitch (1955) interpreted the opisthosoma as having 10 or 11 segments; (3) Kjellesvig-Waering (1969) interpreted the posterior tergites as fused into a 'buckler' or 'triplotergite'; and finally, (4) Dunlop \& Horrocks (1997) interpreted the opisthosoma as having nine tergites (six abbreviated and three fused into a posterior 'buckler') and nine sternites.

3.6.1. Segmentation. The dorsal opisthosoma of the Writhlington material unequivocally consists of 10 tergites plus an anal operculum, which may or may not represent a further segment (see Section 3.6.2). The first six tergites are abbreviated and, in these specimens, medially divided. Posteriorly, there are four tergites which are not fused into a unitary, plate-like 'buckler' (see also Section 5.2.4). This segmentation pattern is also exhibited by the Lower Carboniferous phalangiotarbid Bornatarbus mayasii (Haupt in Nindel, 1955) from the Chemnitz Basin, Saxony, Germany (see Rößler \& Schneider 1997, figs 5-8). The segmentation pattern of the Writhlington fossils described above was also illustrated by Beall (1991, figs 2, 4). However, his composite reconstruction shows the posteriormost tergites fused into a solid tagma (Beall 1991, fig. 1).

The dorsal segmental lines are slightly curved and the ventral ones are straight (Fig. 6a, b). It is difficult to determine whether the posterior tergites are fused into a plate and the segmental lines are just surface furrows (as in trilobite pygidia), or whether they are separate tergites like the anterior six tergites of Phalangiotarbida. Matrix is visible between each of the six anterior tergites (e.g. Fig. 3g, h) and the lateral parts of these anterior tergites form a broken boundary. However, no matrix is visible between the posteriormost four tergites, and there seems to be an uninterrupted lateral margin (Fig. 5g, h) suggesting that the posterior tergites are, to some degree, fused and the segmental lines are surface furrows only. The present authors suspect that, in other (?more derived) taxa, this fusion is complete and the back end of the animal bears a single dorsal plate (e.g. Mesotarbus peteri).

Some specimens (Cd5270A and Cd5300A) indicate paired transversely orientated muscle apodemes located at the lateral margins of tergites 7-9 (Figs 3g, h, 5g, h). This implies that each of these tergites represents a single somite (i.e. no diplotergites). Segment 10 forms a plate that surrounds the anal operculum; this plate is not visibly divided into tergites and sternites. The surface of the dorsal opisthosoma, like that of the carapace, is covered by fine tuberculation.

At least eight sternites are present (Fig. 5a, b), but reference to Mesotarbus peteri suggests that matrix probably covers a further sternite more anteriorly. The four posteriormost sternites are divided into medial and lateral plates (Figs 5f, 6). There are no obvious muscle apodemes on the ventral sternites (e.g. Fig. 5f).

3.6.2. Anal operculum. Pocock (1911) noted the anal operculum, regarded it as a ventral structure, and considered it to represent the tenth opisthosomal segment in his model, a remnant of the posteriormost tergite, shifted ventrally and 

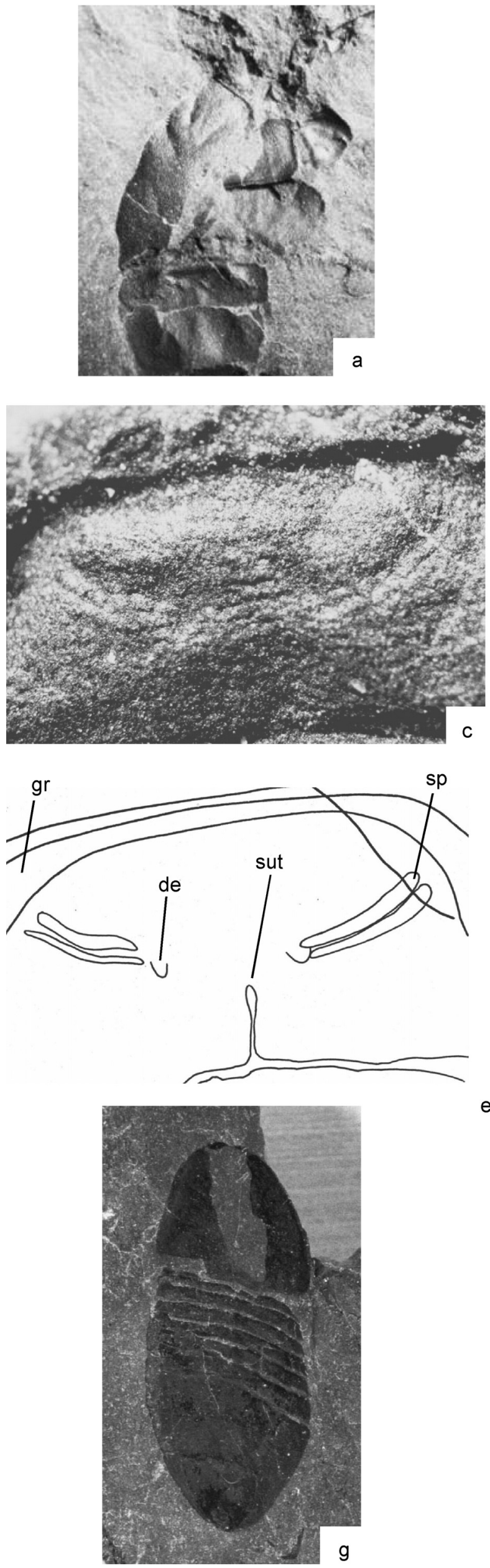
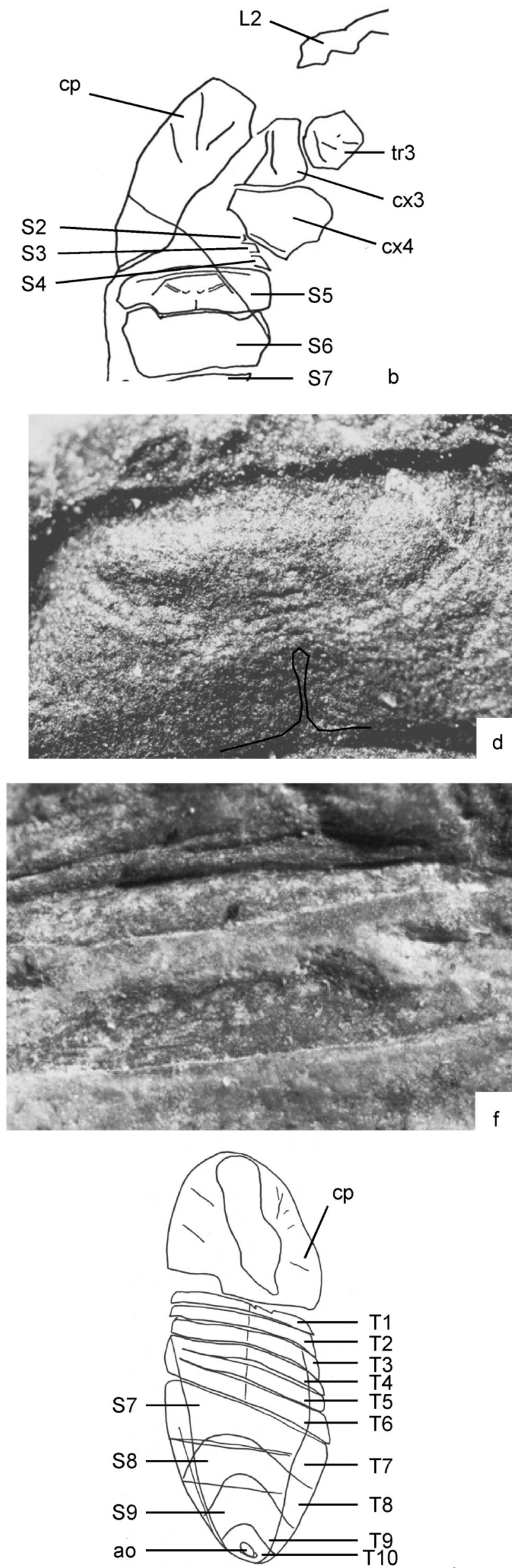
functioning as an anal operculum. This would be the last ontogenetically pre-anal somite. Pocock (1911) did not account for the tenth tergite that surrounds the anal operculum now recognised in the Chemnitz and Writhlington material. Petrunkevitch (1949) omitted the anal operculum from his opisthosomal count because he considered it to be only a differentiation of the last segment; therefore, it would be classed as a post-anal structure, like the dorsally articulated, post-anal structures which are present in other chelicerate taxa like xiphosurans or scorpions.

The Writhlington material is preserved as compressions (see Section 1) and previous workers have mistakenly interpreted ventral structures as dorsal and vice versa (e.g. Petrunkevitch 1913, 1955). However, the anal operculum is unequivocally preserved as a small, unsegmented, dorsal plate in the Writhlington material. It measures c. $1 \mathrm{~mm}$ in diameter and is completely separated from the surrounding tergite 10 (e.g. Fig. $3 \mathrm{~g}, \mathrm{~h}$ ). Thus, we can reject the hypothesis that it is a ventral structure that has become superimposed onto the dorsal surface.

Petrunkevitch (1949) suggested the existence of a right and left valve to the anal operculum. The Writhlington material does not support this. Beall (1991, p. 162) suggested some of the Writhlington material possess anal opercula which lie 'at the intersection of the posterior tergite and sternite' and are 'flanked by unsclerotised pleural integument'. No evidence for this can be seen in any of the material studied. In all other arachnid groups, except some opilionids, the anus opens terminally or ventrally.

\subsection{Respiratory organs}

Petrunkevitch (1955) interpreted the Phalangiotarbida as having one to four pairs of ventral sacs. These curious, probably appendage-derived elements, which may have a role in water balance (Weygoldt 2000), are known from whipspiders, palpigrades and trigonotarbids, but could not be confirmed here in phalangiotarbids. Beall (1991) figured a phalangiotarbid that has a pair of spiracles, based on a composite reconstruction, but he did not comment on either their supposed function or structure.

A specimen of the phalangiotarbid Mesotarbus peteri (MM LL11151) possesses 'two narrow, raised structures on the anterior ventral opisthosoma' (Dunlop \& Horrocks 1997, p. 376, figs 5a, 6a). The first pair was located on the posterior margin of sternite 4 and the second on sternite 5 . A respiratory function seemed the obvious explanation for these structures, but the above authors could not say for certain whether they were related to book lungs or tracheal respiration; the latter was favoured because book lungs 'projecting forward from the spiracle would be expected to impinge on a preceding lung' (Dunlop \& Horrocks 1997, p. 376).

Since the Writhlington phalangiotarbids are mostly preserved as compressions, the sternite divisions are seen through the dorsal surface of some specimens (Cd5282A; Fig. 4g, h). However, two specimens (Cd5266A; Cd5262A and B) clearly display the ventral side (Figs 4a, b, 5a, b, f). Cd5262B shows evidence for two pairs of small, narrow ridges on the median plate of sternite 5 (Fig. 4c, d). The pairs of ridges are raised on a medial mound that is bordered anteriorly and laterally by a deep groove and a high crest, which run parallel to the anterior border of the median plate of the sternite. Each ridge is c. $0.6 \mathrm{~mm}$ in transverse width and extends abaxially across the median plate of sternite 5. The two ridges on each lateral side of the median plate are parallel and very close together; they are separated by only c. $0.02 \mathrm{~mm}$. The ridges on each lateral side are separated by c. $0.75 \mathrm{~mm}$. They are not slit-like structures which traverse the entire plate since they seemingly do not join across this plate.

The posterior margin of the median plate of sternite 5 is medially divided with a very delicate oval-shaped terminus to the suture (Fig. 4c-e). The division is c. $0.5 \mathrm{~mm}$ long (laterally). The presence of this division supports the interpretation that the pairs of ridges do not meet centrally. No structures are seen on any sternite posterior to sternite 5 .

The interpretation favoured here is that the small ridges present on sternite 5 are associated with respiratory organs. They represent paired, delicate structures (Fig. 4c, d) which are found in a similar position on the ventral opisthosoma to the respiratory structures of other arachnids. Posteriorly and medially to the ridge pairs are two slight depressions in the sternite (Fig. 4d), and it is possible that each spiracle may open to the body under these. Depressions in the same relative position to spiracles are seen in some Thelyphonida (Dunlop 1999).

In summary, the positions of the supposed spiracles in the present study are not entirely congruent with that of Dunlop \& Horrocks (1997) (Fig. 4c, d, f) and their first pair of spiracles on segment 4 cannot be confirmed because matrix covers sternites 1-4 on specimen Cd5262B (Fig. 4a, b). The second pair of spiracles noted by Dunlop \& Horrocks (1997) is located anterior to the groove that runs across sternite five (Fig. 4f). Only the counterpart fossil of Mesotarbus peteri is known; the spiracles are deep pits which would represent raised structures in life (Dunlop \& Horrocks 1997). The high crest that runs along the anterior margin of sternite 5 of specimen Cd5262B (Fig. 4e) produces deep pits on the counterpart fossil (Cd5262A; Fig. 5a, b), resembling the proposed spiracles of Mesotarbus peteri (Fig. 4f).

\subsection{Reproductive organs}

The genital opening (gonopore) is present on the second opisthosomal somite in all known arachnids, extant or extinct. This region is not visible in its entirety in the Writhlington material and so the precise position of the gonopore is unknown. There are no obvious external genitalia on the opisthosoma (Figs 4a, b, 5a, b) equivalent to, for example, the eurypterid genital appendage (Braddy \& Dunlop 1997), genital verucae in mites or the epigynal plate of more derived female spiders. Possible internal genital structures are equivocal.

Figure 4 Bornatarbus mayasii (Haupt in Nindel, 1955). (a) Cd5262B, part, anterior of specimen, dorsal view showing the putative respiratory structures on sternite 5 , coxae of walking legs 3 and 4 , the impression of the carapace and podomeres of walking leg 2 ; $\times 4 \cdot 8$. Taken under polarising light; (b) Camera lucida drawing of same specimen; (c) Cd5262B, sternite 5 showing putative spiracles and median suture from posterior border of sternite 5 , plus the groove and the crest that runs along the anterior border; $\times 34 \cdot 1$. Immersed in alcohol; (d) Cd5262B, sternite 5 with the median suture highlighted; $\times 34 \cdot 1$; (e) Camera lucida drawing of same specimen; (f) Mesotarbus peteri Dunlop \& Horrocks, 1997: detail of MM LL11151, showing impression of groove on median plate of sternite $5 ; \times 29 \cdot 3$. Immersed in alcohol; $(\mathrm{g})$ Cd5282A, part, whole specimen showing anterior tergites, posterior opisthosoma showing tergite and sternite segmentation pattern, and dorsal anal operculum; $\times 3 \cdot 8$. Taken under polarising light; (h) Camera lucida drawing of same specimen. Abbreviations: (ao) anal operculum; (cp) carapace; (cx 3-4) coxae of walking legs 3 to 4; (de) depression; (gr) groove; (L2) walking leg 2; (sp) putative spiracle; (sut) median suture; (S2-9) sternites 2 to 9; (T1-10) tergites 1 to 10; and (tr 3), trochanter of walking leg 3. 

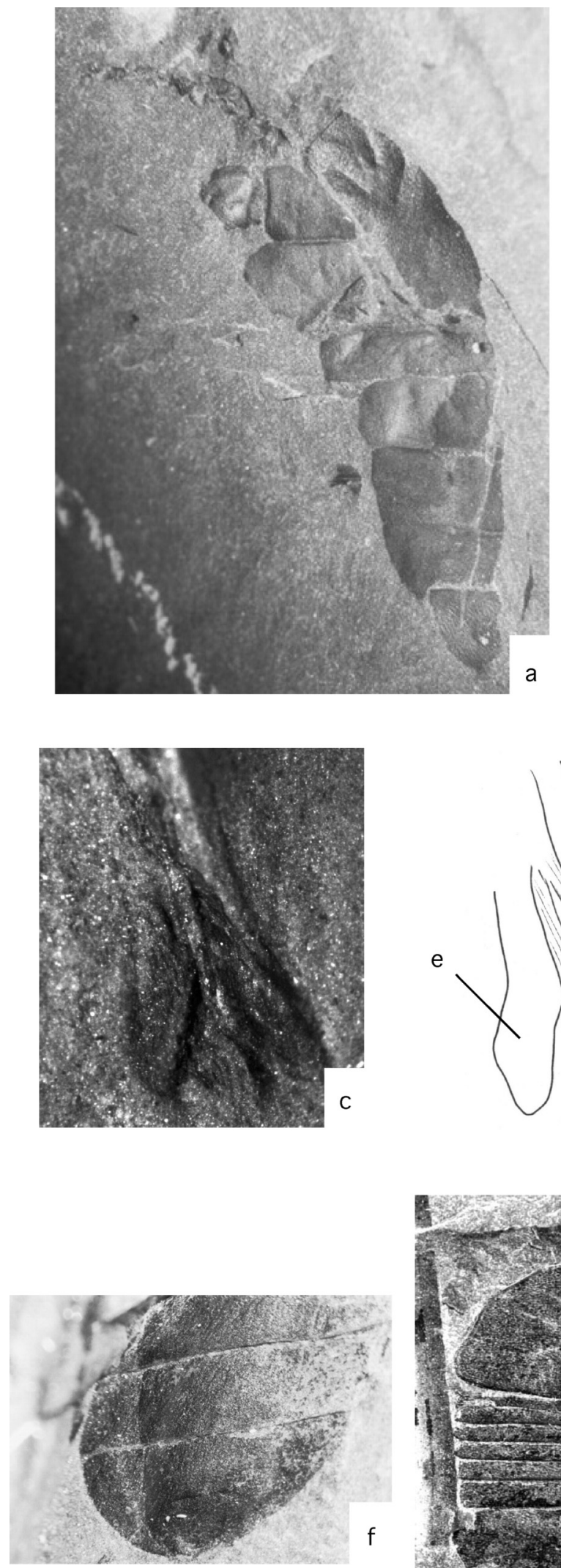

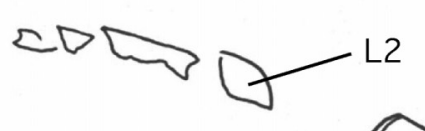
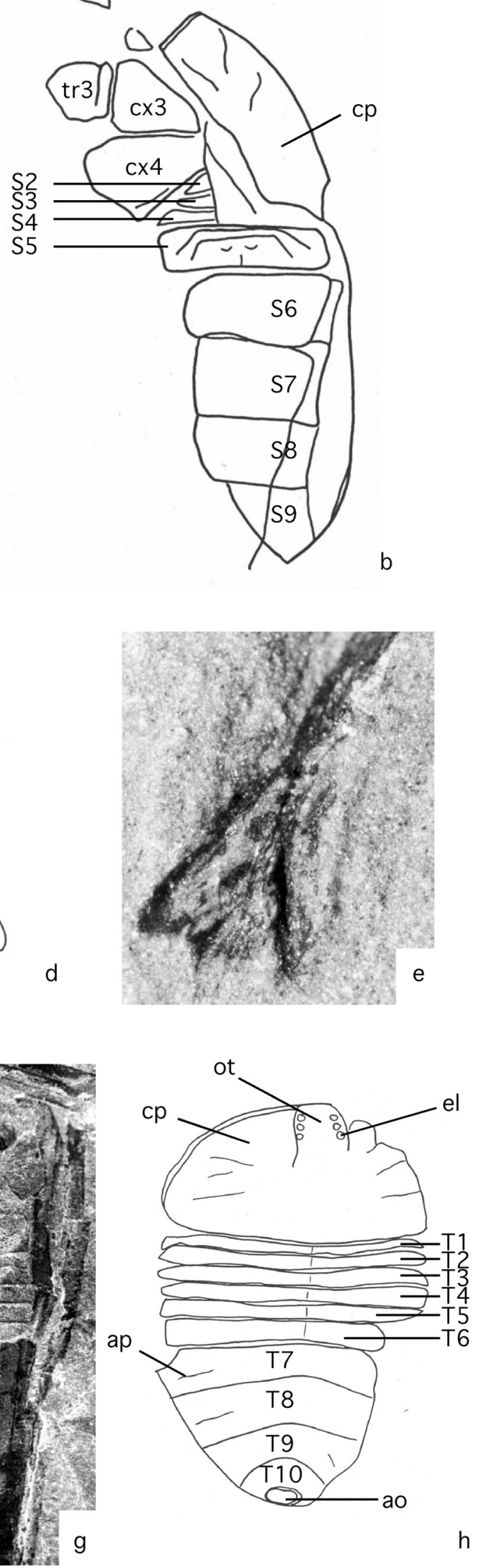

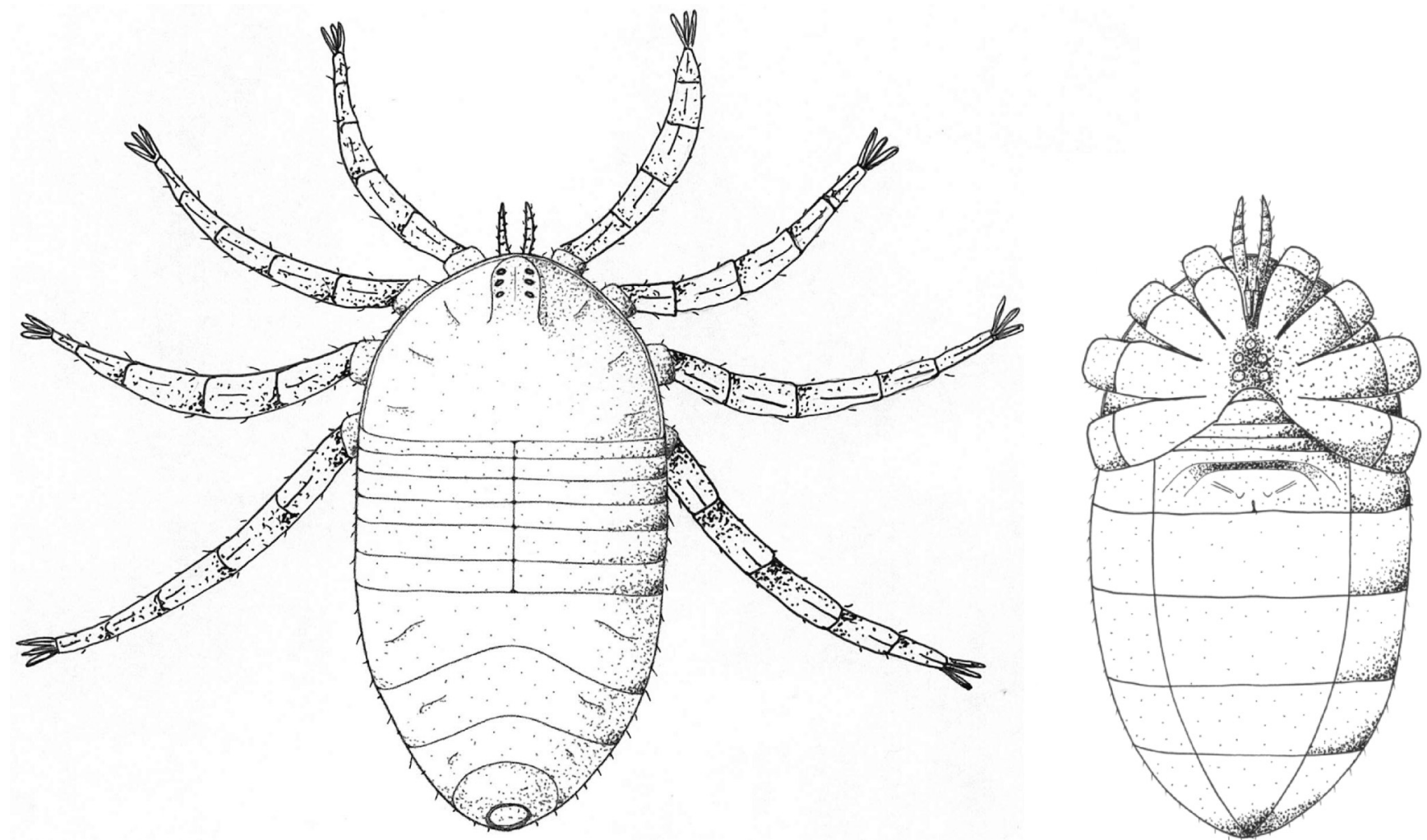

Figure 6 A composite reconstruction based on the material from Writhlington: (left) dorsal surface; and (right) ventral surface. Details of the feeding appendages, walking appendages and ventral anterior segmentation are taken from the Carboniferous phalangiotarbid Mesotarbus peteri Dunlop \& Horrocks, 1997. The sternal region is known from the neotype of Phalangiotarbus subovalis (Woodward, 1872). The retro-deformed width:length ratio is taken from Fitton (2002). The setae are hypothetical.

\subsection{Ornament}

All specimens possess randomly distributed, abundant tuberculation of the cuticle surface (e.g. Fig. 3b). The tubercles are present over the entire body surface. All tubercles appear symmetrical and exhibit the same raised, spheroidal shape. There is no discernible difference in size between the tubercles and they are all c. $0.06 \mathrm{~mm}$ in diameter. Carapace tubercle density is c. $216 \mathrm{~mm}^{-2}$. No pits, distinct trichobothrial bases or any other cuticular structures can be observed. Tuberculation of the internal surface of the cuticle may correspond to the external tubercles (Cd5287B; Fig. 3c). This implies that the external tubercles are not superficial structures and the depth of the tubercles may represent the actual thickness of the cuticle, as in fossil ricinuleids (see Selden 1992 for a discussion).

\section{Palaeoecology}

Writhlington phalangiotarbids are always found in sublithology 'A' of the WGNR (Todd 1991), and their vague similarity to elements of arborescent lycopods (giant clubmosses) - see Thomas \& Cleal (1994) for details of these plants - led Beall (1991) to propose a 'lycopod tree habitat' in which the body shape acts as a sort of camouflage.
This hypothesis is difficult to prove or disprove. In general, a terrestrial mode of life for phalangiotarbids is favoured here because of the possession of a putative tracheal respiratory system (Section 3.7). Kjellesvig-Waering (1969) speculated that phalangiotarbids were aquatic and had gills. Although the Writhlington palaeoenvironment might well have been swampy, the present authors find no morphological characters, such as a plastron, in their material which support an amphibious or aquatic mode of life.

Most arachnids are carnivorous, and it would be reasonable to suggest this feeding habit for Phalangiotarbida too. However, their tiny chelicerae and pedipalps (Section 3.3) tend to argue against them being ambush predators, as suggested by Beall (1984). It has been speculated that phalangiotarbids were scavengers (Dunlop \& Horrocks 1997), comparisons being drawn with extant harvestmen and opilioacarid mites.

\section{Phylogenetic position of Phalangiotarbida}

\subsection{Previous work}

The first report of Phalangiotarbida, Architarbus rotundatus Scudder, 1868, was from Mazon Creek, USA, although it was thought to be a fossil whipspider. Four years later, the first

Figure 5 Bornatarbus mayasii (Haupt in Nindel, 1955). (a) Cd5262A, whole specimen, dorsal view showing the carapace and walking leg 2, and an impression of coxae of walking legs 3 and 4 , and sternites 2-9; $\times 5 \cdot 3$. Taken under polarising light; (b) Camera lucida drawing of same specimen; (c) Cd5273B, part, the structure of the apotele; $\times 28 \cdot 0$. Immersed in alcohol; (d) Camera lucida drawing of the same specimen; (e) Cd5273A, counterpart, the structure of the apotele, $\times 28 \cdot 0$. Immersed in alcohol; (f) Cd5266A, ventral view of posteriormost three sternites, faint impression of tenth tergite and dorsal anal operculum; $\times 4.9$. Immersed in alcohol; (g) Cd5300A, part, dorsal view showing ocular tubercle, dorsal segmentation and anal operculum; $\times 3 \cdot 5$. Taken under polarising light; (h) Camera lucida drawing of the same specimen. Abbreviations: (ao) anal operculum; (ap) apodeme; (cp) carapace; (cx 3-4) coxae of walking legs 3-4; (e) element; (el) eye lens; (L2) walking leg 2; (ot) ocular tubercle; (S2-9), sternites 2 to 9; (T1-10) tergites 1 to 10 ; and (tr 3), trochanter of walking leg 3. 
Table 1. Dataset used in phylogenetic analysis (See Section 5.3 for details).

\begin{tabular}{|c|c|c|c|c|c|c|c|c|c|c|c|c|c|c|c|c|c|c|c|c|c|c|c|c|c|c|c|c|c|c|c|}
\hline & 1 & & & & & & & & & 10 & & & & & & & & & & 20 & & & & & & & & & & 30 & \\
\hline Ancestor & 0 & 0 & 0 & 0 & 0 & 0 & 0 & 0 & 0 & 0 & 0 & 0 & 0 & 0 & 0 & 0 & 0 & 0 & 0 & 0 & 0 & 0 & 0 & 0 & 0 & 0 & 0 & 0 & 0 & 0 & 0 \\
\hline Palpigradi & 2 & 0 & 1 & 0 & 0 & 1 & 0 & 1 & 0 & 0 & 0 & 0 & 0 & 0 & 0 & 0 & 1 & 0 & 0 & 1 & 0 & 1 & 0 & 0 & 0 & 0 & 0 & 0 & 0 & 0 & 0 \\
\hline Araneae & 0 & 0 & 0 & 1 & 1 & 1 & 0 & 1 & 1 & 0 & 0 & 0 & 0 & 0 & 0 & 0 & 0 & 0 & 1 & 1 & 1 & 1 & 0 & 0 & 0 & 0 & 0 & 0 & 0 & 0 & 0 \\
\hline Amblypygi & 0 & 0 & 1 & 1 & 1 & 1 & 0 & 1 & 1 & 0 & 0 & 0 & 0 & 1 & 0 & 0 & 1 & 0 & 0 & 1 & 1 & 1 & 0 & 1 & 0 & 0 & 0 & 0 & 0 & 0 & 1 \\
\hline Thelyphonida & 0 & 1 & 1 & 0 & 1 & 1 & 1 & 1 & 1 & 0 & 0 & 0 & 0 & 1 & 1 & 0 & 1 & 0 & 1 & 1 & 1 & 1 & 0 & 1 & 0 & 0 & 0 & 0 & 0 & 0 & 1 \\
\hline Schizomida & 2 & 1 & 1 & 0 & 1 & 0 & 1 & 1 & 1 & 0 & 0 & 0 & 0 & 1 & 1 & 0 & 1 & 0 & 0 & 1 & 1 & 1 & 0 & 1 & 2 & 0 & 2 & 0 & 0 & 1 & 1 \\
\hline Ricinulei & 0 & 0 & 0 & 0 & 3 & 0 & 0 & 1 & 1 & 0 & 0 & 0 & 0 & 0 & 1 & 1 & 0 & 1 & 0 & 1 & 0 & 0 & 0 & 0 & 2 & 0 & 2 & 1 & 1 & 0 & 0 \\
\hline Acari & ? & 0 & 0 & 0 & ? & 0 & 0 & 1 & 0 & 0 & 0 & 0 & 0 & 0 & 1 & 1 & 0 & 0 & 0 & 1 & 0 & 0 & 0 & 0 & 0 & 0 & 0 & 1 & 0 & 0 & 0 \\
\hline Opiliones & 1 & 2 & 0 & 0 & 2 & 0 & 0 & 0 & 0 & 0 & 1 & 0 & 0 & 0 & 0 & 0 & 0 & 0 & 0 & 0 & 0 & 1 & 1 & 0 & 1 & 0 & 0 & 2 & 0 & 0 & 0 \\
\hline Scorpiones & 1 & 2 & 0 & 0 & 2 & 0 & 0 & 0 & 0 & 0 & 1 & 0 & 1 & 0 & 0 & 0 & 0 & 1 & 0 & 0 & 0 & 1 & 1 & 0 & 1 & 1 & 1 & 2 & 1 & 1 & 0 \\
\hline Pseudoscorpiones & 1 & 2 & 0 & 0 & 2 & 0 & 0 & 0 & 2 & 1 & 0 & 1 & 1 & 0 & 0 & 0 & 0 & 1 & 0 & 1 & 0 & 1 & 1 & 0 & 1 & 1 & 1 & 2 & 2 & 1 & 0 \\
\hline Solifugae & 2 & 2 & 0 & 0 & 4 & 0 & 0 & 0 & 2 & 1 & 0 & 1 & 0 & 0 & 0 & 0 & 1 & 1 & 0 & 1 & 0 & 0 & 2 & 0 & 2 & 0 & 1 & 1 & 1 & 1 & 0 \\
\hline Phalangiotarbida & 0 & 3 & 1 & $?$ & $?$ & $?$ & $?$ & $?$ & $?$ & $?$ & $?$ & 0 & 0 & 0 & $?$ & $?$ & 0 & 0 & $?$ & 1 & $?$ & 1 & $?$ & $?$ & $?$ & $?$ & $?$ & $?$ & $?$ & $?$ & 0 \\
\hline Trigonotarbida & 0 & 0 & 0 & $?$ & ? & ? & ? & 1 & 1 & 0 & 0 & 0 & 0 & 0 & 0 & 0 & 0 & 0 & ? & 0 & $?$ & 0 & 2 & ? & $?$ & ? & ? & 2 & $?$ & ? & 0 \\
\hline
\end{tabular}

40

50

60

\begin{tabular}{|c|c|c|c|c|c|c|c|c|c|c|c|c|c|c|c|c|c|c|c|c|c|c|c|c|c|c|c|c|c|c|c|c|}
\hline Ancestor & 0 & 0 & 0 & 0 & 0 & 0 & 0 & 0 & 0 & 0 & 0 & 0 & 0 & 0 & 0 & 0 & 0 & 0 & 0 & 0 & 0 & 0 & 0 & 0 & 0 & 0 & 0 & 0 & 0 & 0 & 0 & 0 \\
\hline Palpigradi & 0 & 0 & 0 & 1 & 0 & 1 & 0 & 1 & 1 & 1 & 1 & 0 & 0 & 0 & 1 & 0 & 4 & 1 & 0 & 0 & 0 & 0 & 2 & 0 & $?$ & $?$ & $?$ & 0 & 0 & 0 & 1 & 1 \\
\hline Araneae & 1 & 0 & 0 & 1 & 0 & 1 & 1 & 1 & 1 & 0 & 0 & 0 & 0 & 1 & 1 & 0 & 1 & 0 & 1 & 0 & 0 & 1 & 1 & 1 & 0 & 0 & 0 & 0 & 0 & 1 & 0 & 1 \\
\hline Thelyphonida & 1 & 1 & 0 & 1 & 1 & 1 & 1 & 1 & 2 & 1 & 1 & 1 & 0 & 1 & 1 & 1 & 1 & 0 & 1 & 0 & 0 & 1 & 1 & 1 & 1 & 1 & 1 & 0 & 0 & 1 & 1 & 1 \\
\hline Schizomida & 1 & 1 & 0 & 1 & 1 & 1 & 1 & 1 & 2 & 1 & 1 & 1 & 0 & 1 & 1 & 1 & 3 & 1 & 1 & 0 & 0 & 1 & 1 & 1 & 1 & 1 & 1 & 0 & 0 & 1 & 1 & 1 \\
\hline Ricinulei & 0 & 0 & 0 & 2 & 0 & 1 & 0 & 0 & 2 & 1 & 0 & 0 & 1 & 1 & 0 & - & 3 & 1 & 0 & 1 & 0 & 1 & 1 & 0 & 0 & 0 & 0 & 0 & 1 & 1 & 1 & 1 \\
\hline Opiliones & 1 & 0 & 0 & 3 & 0 & 0 & 0 & 0 & 2 & 0 & 0 & 0 & 0 & 1 & 0 & - & 4 & 0 & 0 & 1 & 0 & 0 & 1 & 0 & 0 & 0 & 0 & 1 & 0 & 0 & 0 & 0 \\
\hline Scorpiones & 1 & 0 & 0 & 1 & 0 & 0 & 0 & 0 & 0 & 0 & 0 & 0 & 0 & 1 & 1 & 0 & 0 & 0 & 0 & 0 & 0 & 0 & 0 & 0 & 1 & 0 & 0 & 0 & 0 & 1 & 0 & 0 \\
\hline Pseudoscorpiones & 1 & 0 & 1 & 2 & 0 & 0 & 0 & 0 & 2 & 0 & 0 & 0 & 0 & 1 & 1 & 0 & 2 & 1 & 0 & 1 & 1 & 0 & 1 & 0 & 1 & 0 & 1 & 0 & 0 & 0 & 0 & 0 \\
\hline Solifugae & 1 & 0 & 1 & 2 & 0 & 1 & 0 & 0 & 2 & 0 & 0 & 0 & 0 & 1 & 0 & - & 2 & 0 & 0 & 1 & 1 & 0 & 2 & 0 & 0 & 0 & 0 & 0 & 0 & 1 & 1 & 0 \\
\hline Phalangiotarbida & $?$ & $?$ & 0 & 0 & $?$ & 0 & 0 & 0 & $?$ & 0 & 0 & $?$ & 0 & $?$ & $?$ & $?$ & 1 & 1 & 0 & 1 & 0 & $?$ & $?$ & $?$ & $?$ & $?$ & $?$ & $?$ & $?$ & $?$ & $?$ & $?$ \\
\hline Trigonotarbida & $?$ & $?$ & 0 & 1 & $?$ & 1 & $?$ & 1 & $?$ & 1 & 0 & $?$ & 1 & 1 & 0 & - & $?$ & 0 & 1 & 0 & 0 & $?$ & $?$ & $?$ & $?$ & $?$ & $?$ & $?$ & $?$ & $?$ & $?$ & ? \\
\hline
\end{tabular}

European species, Architarbus subovalis, was described from the Lancashire Coal Measures (Woodward 1872; Haughton 1877). Haase (1890) erected Phalangiotarbi (later emended to Phalangiotarbida) as a suborder of Opiliones (harvestmen) containing only a single new genus, Phalangiotarbus, which he created for $A$. subovalis. He left $A$. rotundatus in the genus Architarbus Scudder, 1868 and still regarded it as a whipspider. Fritsch (1904) later referred all known phalangiotarbids to a single family, Architarbidae, within his broad opilionid suborder, Meridogastra.

Pocock (1910) agreed with Haase (1890) that A. subovalis and $A$. rotundatus were generically distinct, but questioned whether the phalangiotarbids were truly opilionids or a distinct order. Subsequently, Pocock (1911) raised Phalangiotarbi to ordinal status. Little further work was published on phalangiotarbids until that of Petrunkevitch in 1945. He introduced a new ordinal name, Architarbi (later emended to Architarbida), in preference to Phalangiotarbi on the grounds that his new name was derived from the better-preserved material of the genus Architarbus (see Petrunkevitch 1945). This replacement name was deemed unnecessary by later authors (e.g. Kjellesvig-Waering 1969; Patrick 1989; Selden 1993; Dunlop 1996b).

Petrunkevitch $(1949,1955)$ placed Scorpiones, Pseudoscorpiones, Opiliones, Phalangiotarbida and Acari together in a new subclass, Latigastra, based on their possession of a broad prosoma-opisthosoma junction, but the relationships within this subclass were not further resolved. The above author highlighted the similarity of the coxo-sternal regions of the phalangiotarbids to that of cyphophthalmid Opiliones, and suggested that the latter had descended from the former or, at least, had a shared a common ancestor (see also Dunlop 1996b).

Five phylogenetic relationships have been more recently proposed for the Phalangiotarbida: (1) referral to an infraclass Opilionoidea, along with the Ricinulei, Opiliones and Acari (Savory 1971); (2) placement with Ricinulei and Acari in a taxon Cryptognomae (van der Hammen 1977); (3) placement as a relatively early derivative arachnid group of a similar grade of organization to Pedipalpi and the (extinct and polyphyletic) Stethostomata (Grasshoff 1978); (4) as sister group to Opiliones + Acari (Beall \& Labandeira, 1990); and (5) as related to opilioacariform mites and tentatively placed as a sub-group of the Acari (Dunlop 1995).

\subsection{Discussion of characters}

5.2.1. Prosomal characters. 1 . Carapace [0, undivided; 1 , transverse segmental furrows; 2, divided]. Phalangiotarbida show division of the anterior part of the carapace by furrows (Fig. 3a; Section 3.1), but it is likely that these furrows represent the insertion sites of endosternal suspensor muscles and are not 'remnants of tergal margins' (cf. Shultz 1990) since they do not traverse the full width of the carapace. Therefore, phalangiotarbids have been scored as possessing an undivided carapace. 
2. Intercoxal sternal region [0, broad throughout; 1 , narrow posteriorly; 2 , narrow throughout; 3 , narrow anteriorly]. The plesiomorphic condition of the coxosternal region of Arachnida is a simple sternum, broad throughout, that is bordered laterally by the coxae of the prosomal appendages, and posteriorly by the sternite or appendages of the first opisthosomal segment (as in Trigonotarbida; Dunlop 1994a). The posterior intercoxal region is greatly reduced in Thelyphonida and Schizomida by medial expansion of the posterior coxae, and reduced throughout in Opiliones, Scorpiones, Pseudoscorpiones and Solifugae (Shultz 1990). In Phalangiotarbida, the anterior intercoxal region is reduced, the leg 1 coxa abut one another and together obscure the pedipalpal coxae in ventral view. Therefore, this condition has been coded as a new, autapomorphic, character state 'narrow anteriorly'.

3. Prosomal sternite [0, uniform; 1, with distinct sclerites]. A single, undivided sternum is the primitive condition for Arachnida (Shultz 1990). Phalangiotarbida possess the derived condition of distinct sternal sclerites (Section 3.4).

4. Postcerebral pharynx [0, absent or poorly developed; 1 , well developed]. The portion of the digestive tract anterior to the central nervous system is termed the 'pharynx'. Dimple-like depressions in the carapace of fossil arachnids have been interpreted as evidence of muscle attachment sites which operate this organ (Shear et al. 1987). However, this idea has been rejected since these depressions are known to represent the insertion sites of endosternal suspensor muscles in some extant arachnid orders (Shultz 1990). This character state is unknown for Phalangiotarbida.

5-7. Prosomal internal anatomy. (5) Prosomal endosternite, segmental components [0, five; 1 , four; 2 , two; 3 , one; 4 , absent]. (6) Dorsal endosternal suspensor of the fourth postoral segment with anterolateral carapacal insertion $[0$, absent; 1, present]. (7) Fenestrate endosternite [0, absent; 1, present]. These character states are unknown for Phalangiotarbida.

5.2.2. Mouthparts. 8. Tritosternum [0, absent; 1 , present]. Trigonotarbida possess a tritosternum (Dunlop 1996c). This character state is unknown for Phalangiotarbida.

9. Chelicerae formed by $[0$, three segments, the last two forming a chelae; 1 , two segments, subchelate; 2 , two segments, chelate, articulating at a ventral or ventrolateral joint]. An unpublished manuscript by Kjellesvig-Waering figures the holotype of Geratarbus lacoei (Scudder 1890), U. S. National Museum No. 37966, with putative chelicerae preserved. However, this specimen was not available for study by the authors since it is currently on loan to Dr D. C. Fisher. The chelicerae were described by Kjellesvig-Waering as 'very small structures' which 'occupy a position directly above the narrow coxae of the pedipalps ... the fixed ramus is very short, on a rather long manus [and the] free finger [is] strongly falcate'. However, this character state cannot be verified here and is coded as unknown for Phalangiotarbida.

10. Chelicerocarapacal articulation [0, absent; 1 , present]. Known to be absent in Trigonotarbida (Giribet et al. 2002), but unknown in Phalangiotarbida.

11. Stomotheca $[0$, absent; 1 , present]. The stomotheca is a specific preoral cavity where extraintestinal digestion takes place. It is coded as absent in Trigonotarbida (Dunlop 1994b) and unknown in Phalangiotarbida.

12. Rostrum [0, absent; 1 , present]. The labrum in Solifugae and Pseudoscorpiones projects anteriorly between the bases of the chelicerae, forming a unique beak-like structure termed a 'rostrum'. This is coded as absent in Trigonotarbida (Shear et al. 1987) and Phalangiotarbida (Dunlop \& Horrocks 1997; Section 3.3).

13. Scorpionoid pedipalpal chelae [0, absent; 1 , present]. The pedipalps of Trigonotarbida (Shear et al. 1987) and
Phalangiotarbida (Dunlop \& Horrocks 1997; Section 3.3) are pediform, not chelate.

14. Raptorial pedipalps [0, absent; 1 , present]. The pedipalps of Trigonotarbida and Phalangiotarbida are pediform, not raptorial.

15. Pedipalpal coxae [0, free; 1 , fused medially]. Unfused pedipalpal coxae is the plesiomorphic condition for the Arachnida. The pedipalpal coxae are unfused in Trigonotarbida (Dunlop 1996c). Phalangiotarbida are coded as unknown; although their walking leg coxae (ch.18) are unequivocally unfused, it is unknown whether their pedipalpal coxae were too.

16. Movable subcapitulum [0, absent; 1 , present]. Although coded as unknown in Trigonotarbida by Giribet et al. (2002), it is thought that a movable subcapitulum is absent in Trigonotarbida (Dunlop 1996c) and it is coded so here. The character state is unknown in Phalangiotarbida.

5.2.3. Walking legs. 17 . Leg $1[0$, unmodified, ambulatory; 1, elongate, tactile]. Phalangiotarbida have an unmodified leg 1 .

18. Movable coxae [0, present; 1 , absent]. All coxae of all the walking legs of the Trigonotarbida are free (Giribet et al. 2002). This is thought to be the plesiomorphic chelicerate condition (Shultz 1990). Coxal movement is absent in Ricinulei, Scorpiones, Pseudoscorpiones and Solifugae (Shultz 1990). The coxae of the walking legs of Phalangiotarbida are not obviously fused.

19. Musculi laterales [0, absent; 1 , present]. This internal character state is unknown in Trigonotarbida and Phalangiotarbida.

20. Coxal endites [0, present; 1 , absent]. The medial surface of each coxa in Xiphosura and Eurypterida is equipped with a process, termed an 'endite', and this condition is probably primitive in Arachnida (Selden 1981; Giribet et al. 2002). Although endites are present on the coxae of legs 1 and 2 in Scorpiones, and many opilionids, they are absent on the walking legs of all other Recent arachnids. Endite-like projections are inferred from the shape of the coxae of some Trigonotarbida (Dunlop \& Horrocks 1996) and are present on Trigonotarbida from the Rhynie Chert (Dunlop 1997). They are not seen in Phalangiotarbida (Figs 3d, 4a, b).

21. Coxotrochanteral joint [0, simple; 1 , complex]. This character is unknown in Phalangiotarbida.

22. Femur, legs 3 and 4 [0, divided; 1, undivided]. Most arachnid walking appendages comprise seven podomeres: coxa, trochanter, femur, patella, tibia, divided tarsus and pretarsus (apotele). The third and fourth walking legs in Ricinulei, early derivative Acari and Solifugae have eight podomeres rather than seven (Shultz 1990) on legs 3 and 4 (Dunlop 1996c). Certain trigonotarbids have an extra podomere termed an 'annulus' between the trochanter and the femur of all walking legs (Dunlop 1996c). These extra podomeres are regarded as homologous and as the plesiomorphic condition for Arachnida (Dunlop 1996c; Shultz 1990). The Phalangiotarbida exhibit the derived state of undivided leg femora of walking legs 3 and 4 (Dunlop \& Horrocks 1997).

23-30. Joints and musculature. (23) Femorpatellar joint [0, hinge; 1, bicondylar; 2, monocondylar]. (24) Femorpatellar flexor muscle, insertion [0, symmetrical; 1 , asymmetrical]. (25) Posterior transpatellar muscle, origin [0, dorsoposterior surface of femur and/or posterior surface of patella; 1, distal process of femur; 2, absent]. (26) Patellotibial extensor muscle [0, absent; 1, present]. (27) Anterior transpatellar muscle, insertion on tibia [0, anterior; 1 , ventral; 2, absent]. (28) Patellotibial joint [0, monocondylar; 1 , hinge; 2, bicondylar]. 
(29) Anterior patellotibial muscle, insertion on tibia [0, anterior; 1, ventral; 2, absent]. (30) Posterior patellotibial muscle [0, present; 1 , absent]. All these character states are unknown in Phalangiotarbida.

31. Telotarsus with three or more tarsomeres [0, absent; 1 , present]. The tarsus, the penultimate segment of the walking appendage, is usually divided into at least two tarsomeres: a proximal basi- (or meta-) tarsus and distal telotarsus. The latter is subdivided in many arachnid orders, but the number of tarsomeres varies between taxa and often within a taxon (Shultz 1990). Phalangiotarbid walking legs are not preserved in detail in either the Writhlington material or Mesotarbus peteri (Dunlop \& Horrocks 1997). However, Pocock (1911) figured phalangiotarbids with an undivided telotarsus, and hence, the character state is coded as absent for Phalangiotarbida.

32-33. (32) Claw depressor muscle, patellar head [0, absent; 1, present]. (33) Claw depressor muscle, origin on posterior wall of patella [0, absent; 1 , present]. These limb musculature characters from Shultz (1990) are unknown in Trigonotarbida and Phalangiotarbida.

34. Empodium (= pulvillus) $[0$, absent; 1 , present $]$. The apotele in adult Pseudoscorpiones and Solifugae is present as an eversible organ known as an empodium (Shultz 1990). This is absent in Phalangiotarbida (see Section 3.5).

35. Claws of legs 3 and 4 [0, a single triramous or multiramous claw, all elements of similar length; 1, a single triramous or multiramous claw, two larger lateral elements, and a smaller median element; 2 , two claws; 3 , one claw]. A trifurcate apotele, with all elements of similar size, is seen in the Early Devonian xiphosuran Weinbergina opitzi, the Early Devonian scorpion Palaeoscorpius devonicus, pycnogonids and trilobites. Therefore, it may be the plesiomorphic chelicerate condition (Dunlop 2002). The apotele of Phalangiotarbida is roughly $1 \mathrm{~mm}$ wide, is trifurcate in structure and clearly has three elements of approximately equal length (see Section 3.5). This structure of the apotele is supported by a figure of a specimen of Mesotarbus hindi (Pocock 1911), NHM In.22839, in Kjellesvig-Waering's unpublished manuscript, with apoteles preserved of the same structure. The structure of the Phalangiotarbida apotele implicitly shows the plesiomorphic arachnid condition. The arrangement of insertion points of the muscles which operate the elements of the apotele can be phylogenetically informative (Shultz 1990; Dunlop 2002), but these are not preserved in this fossil material.

36. Tarsal organ $[0$, absent; 1 , present]. This character state is unknown in Phalangiotarbida.

5.2.4. Opisthosoma. 37. First opisthosomal segment [0, broad; 1, narrow]. Phalangiotarbida, like Acari, Opiliones, Scorpiones and Pseudoscorpiones, retain the broad connection between the prosoma and opisthosoma that is widely considered the primitive condition for Arachnida (Shultz 1990). However, this character state could be subject to many functional constraints, and the homology of narrow (derived) pedicels among several arachnid lineages has been disputed (Shear et al. 1987).

38. Genital segment divided, incorporated into pedicel $[0$, absent; 1, present]. This character state is inapplicable in Phalangiotarbida.

39. Genital sternite overlapping third opisthosomal sternite $[0$, absent; 1 , present]. The definition of this 'megoperculatan' character adopted here is that both a genital sternite and a third opisthosomal sternite must be present, the genital plate projecting rearwards and overlapping the sternite of the third opisthosomal sternite (Shultz 1990). The character state appears to be present in Trigonotarbida (Dunlop 1996c, fig. 4;
Dunlop 1999), but is absent in Phalangiotarbida (Dunlop \& Horrocks 1997, fig. 7).

40. Post-genital appendages [0, opercular and/or lamellar; 1, poorly sclerotised or eversible; 2, absent]. This character state is unknown in Phalangiotarbida.

41. Pygidium of three segments [0, absent; 1 , present]. The Phalangiotarbida do not have a three-segmented pygidium with three ring-like segments, since only the two posteriormost segments are shortened (e.g. Fig. 3g, h).

42. Pygidial flagellum [0, absent; 1 , present]. A flagellum, as seen in Palpigradi, Thelyphonida and Schizomida (Shultz 1990), is absent in Phalangiotarbida.

43. Pygidial defensive glands [0, absent; 1 , present]. This character state is unknown in Phalangiotarbida.

44. Opisthosomal tergites divided longitudinally into median and lateral plates [0, absent; 1 , present]. Tergites are divided into median and lateral plates only in Trigonotarbida and Ricinulei. This character state is probably derived, but also occurs in some potential outgroups (e.g. xiphosurans). Phalangiotarbida do not have divided tergites (Fig. 3g, h).

5.2.5. Sense organs. 45-47. (45) Slit sensilla [0, absent; 1 , present]. (46) Trichobothria [0, absent; 1, present]. (47) Tibial trichobothria with 2-2-1-1 distribution [0, absent; 1 , present]. These are unknown (45-46) or inapplicable (47) in Phalangiotarbida.

48. Lateral eyes [0, compound; 1 , aggregate, with six principal lenses; 2, aggregate, with four lenses; 3, vestigial; 4, absent]. Among Recent arachnids, six principal lateral eyes occur in Araneae, Amblypygi, Thelyphonida and some Acari. Trigonotarbida with six lateral eye lenses have been described (Shear et al. 1987). However, it is possible that these specimens may represent the carapaces of early forms of extant tetrapulmonates (Dunlop 1997) and, for this reason, this character state has been coded as unknown in Trigonotarbida. Six eye lenses are present in Phalangiotarbida (Section 3.2) and these are scored here as three pairs of lateral eyes.

49. Medial eyes [0, present; 1 , absent]. Medial eyes are present in all chelicerates except Pseudoscorpiones, Schizomida, Ricinulei and Palpigradi. Trigonotarbida possess medial eyes (Dunlop 1996a), but they are considered here as absent in Phalangiotarbida (see Section 3.2).

5.2.6. Respiratory organs. 50 . Book lungs $[0$, absent; 1 , present]. Phalangiotarbida are coded as lacking book lungs, since there is stronger evidence that they possess a tracheal system (see Section 3.7).

51. Tracheal system [0, absent; 1 , present $]$. Because of possible closely placed spiracles, Phalangiotarbida are tentatively scored as possessing a tracheal system (see Section 3.7).

52. Sternal stigmata on opisthosomal segments 3 and $4[0$, absent; 1, present]. Paired stigmata opening on the ventral surfaces of opisthosomal segments 3 and 4 are present in Pseudoscorpiones and Solifugae (Shultz 1990). The spiracles of Phalangiotarbida are here suggested to open on at least opisthosomal segment 5 (see Section 3.7).

5.2.7. Reproduction/development/excretion. 53-63. (53) Spermatozoan nucleus with microtubule array [0, absent; 1 , present]. (53) Spermatozoan axoneme [0, free; 1, coiled; 2, absent]. (54) Spermatozoan axoneme, 9+3 microtubule arrangement [0, absent; 1, present]. (56) Stalked spermatophore [0, absent; 1, present]. (57) Female grasps male opisthosoma during mating [0, absent; 1 , present]. (58) Gonoporal brood sac [0, absent; 1 , present]. (59) Ovipositor [0, absent; 1 , present]. (60) Hexapodal instar [0, absent; 1, present]. (61) Malpighian tubules [0, absent; 1, present]. (62) Coxal gland orifice, leg 3 [0, present; 1 , absent]. (63) Coxal gland orifice, leg 1 [0, absent; 1 , present]. All these characters must be scored as unknown for Phalangiotarbida. 


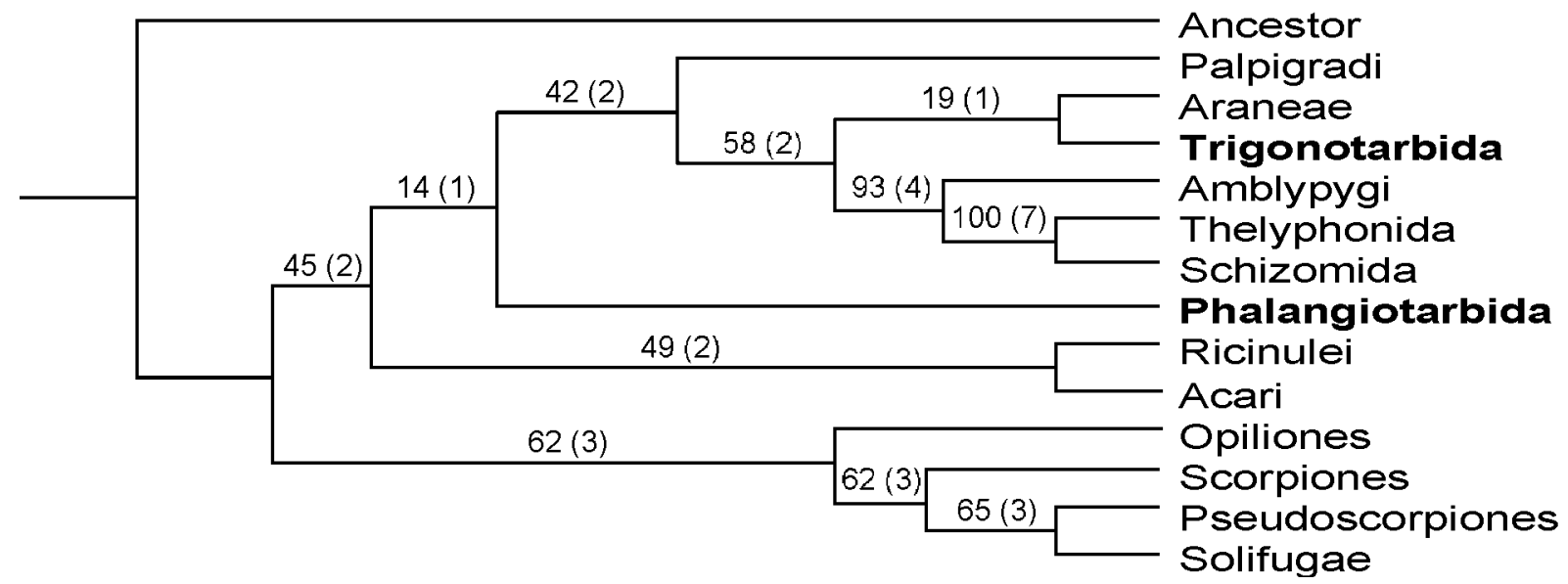

Figure 7 The MPT recovered from the analysis. Fossil taxa are shown in bold type. The bootstrap values are given above the appropriate branches and the corresponding branch support values are given in brackets.

\subsection{Results}

The principal aim of the present analysis was to recover a robust position for Phalangiotarbida when scored for existing arachnid characters. There was no attempt to investigate controversial issues here such as arachnid monophyly and the disputed position of scorpions; see Weygoldt (1998) and Dunlop \& Braddy (2001) for further details. The dataset is given in Table 1 . The PTP test $(P<0 \cdot 001)$ indicated that there was significant cladistic structure in the dataset; further analyses could then be conducted confidently.

When an analysis of the entire dataset was undertaken, one MPT was obtained (Fig. 7). The MPT has a tree length (TL) of 150 steps and a CI of $0 \cdot 547$ [homoplasy index $(\mathrm{HI})=0 \cdot 453$; (RI) $0 \cdot 614$; rescaled consistency index $(\mathrm{RC})=0 \cdot 336]$. High bootstrap values are obtained on some branches, while those clades containing the fossil taxa have lower bootstrap values (Fig. 7). The relationships between the extant taxa are the same as those recovered by Shultz (1990, fig. 4). This is not surprising since the dataset used here follows that of Shultz (1990) very closely. The phylogenetic position of Phalangiotarbida is unaffected if the assumption of character 9 coded as ' 1 ' and character 15 coded as ' 0 ' is made ( $\mathrm{TL}=151, \mathrm{CI}=0 \cdot 543, \mathrm{HI}=0 \cdot 457$, $\mathrm{RI}=0 \cdot 608, \mathrm{RC}=0 \cdot 330$ ).

An analysis of the dataset excluding the fossil taxa (Trigonotarbida and Phalangiotarbida), and the uninformative character 44, produced one MPT of the same topology as that obtained by Shultz (1990, fig. 4) $(\mathrm{TL}=140, \quad \mathrm{CI}=0 \cdot 572$, $\mathrm{HI}=0 \cdot 429, \mathrm{RI}=0 \cdot 630, \mathrm{RC}=0 \cdot 360)$. High bootstrap values are obtained on most branches, the lowest values being for the Ricinulei and Acari clade, and the placement of Scorpiones as the sister group to the Haplocnemata (Pseudoscorpiones and Solifugae).

\subsection{Discussion}

Phalangiotarbid autapomorphies include the narrowed region between the leg 1 coxae (character 2), and we can add to this the following characters not scored in the matrix: six abbreviated anterior tergites, a dorsal anus and longitudinally divided sternites (see also Section 6). Phalangiotarbida display a unique mosaic of characters and do not possess clear apomorphies which unequivocally unite them with any known arachnid taxon, extant or extinct. Seventeen of the 24 characters scoreable for Phalangiotarbida in the present study exhibit what is thought to be the plesiomorphic arachnid condition (see Section 5.3). This makes it harder to resolve a sister group and implies that phalangiotarbids may be rather early derivative arachnids. However, they do possess some derived characters which allow them to be tentatively placed within the Arachnida.

Parsimony analysis resolves Phalangiotarbida as the sister group to Palpigradi and Tetrapulmonata (Fig. 7). Interestingly, this result is not congruent with any previously proposed phylogenetic relationship for the Phalangiotarbida (see Section 5.1).

The apomorphies which support the close relationship between Phalangiotarbida and Shultz's Micrura (Acaromorpha, Palpigradi and Tetrapulmonata) are: (1) the absence of coxal endites (convergent with Pseudoscorpiones and Solifugae) (character 20); (2) six lateral eyes (reduced in Ricinulei, Palpigradi and Schizomida) (character 48); and (3) the absence of medial eyes (convergent with Pseudoscorpiones) (character 49) (Fig. 8).

The apomorphies that support a sister-group relationship of Phalangiotarbida to Megoperculata sensu Shultz (i.e. Palpigradi+Tetrapulmonata) are: (1) the possession of a prosomal sternite with distinct sclerites (with an implicit reversal in Araneae and Trigonotarbida) (character 3); and (2) the undivided femora of walking legs 3 and 4 (convergent with Opiliones, Scorpiones and Pseudoscorpiones) (character 22) (Fig. 8).

However, Phalangiotarbida can be excluded from Megoperculata since it lacks the large genital plate that defines this group (character 39) (Fig. 8). (Phalangiotarbida+ Megoperculata) is not a particularly robust result since the two supporting characters (i.e. divided sternum and undivided femora) are rather minor features, and this model requires a reversal to the unitary sternum of spiders and trigonotarbids. Phalangiotarbids really have a quite unusual and unique gross morphology among the arachnids and the present study demonstrates the difficulties in placing them (see also Section 5.1), even under cladistic analysis. Missing data remain a problem and further details of the mouthparts would probably help to resolve the issue further.

\section{Systematic Palaeontology}

Order Phalangiotarbida Haase, 1890

Emended diagnosis. Palaeozoic arachnids with a broad prosoma-opisthosoma junction. Carapace semi-circular with a single median ocular tubercle bearing six eye lenses. Chelicerae and pedipalps minute. Sternum composed of four or five sclerites with the anterior intercoxal region reduced. 


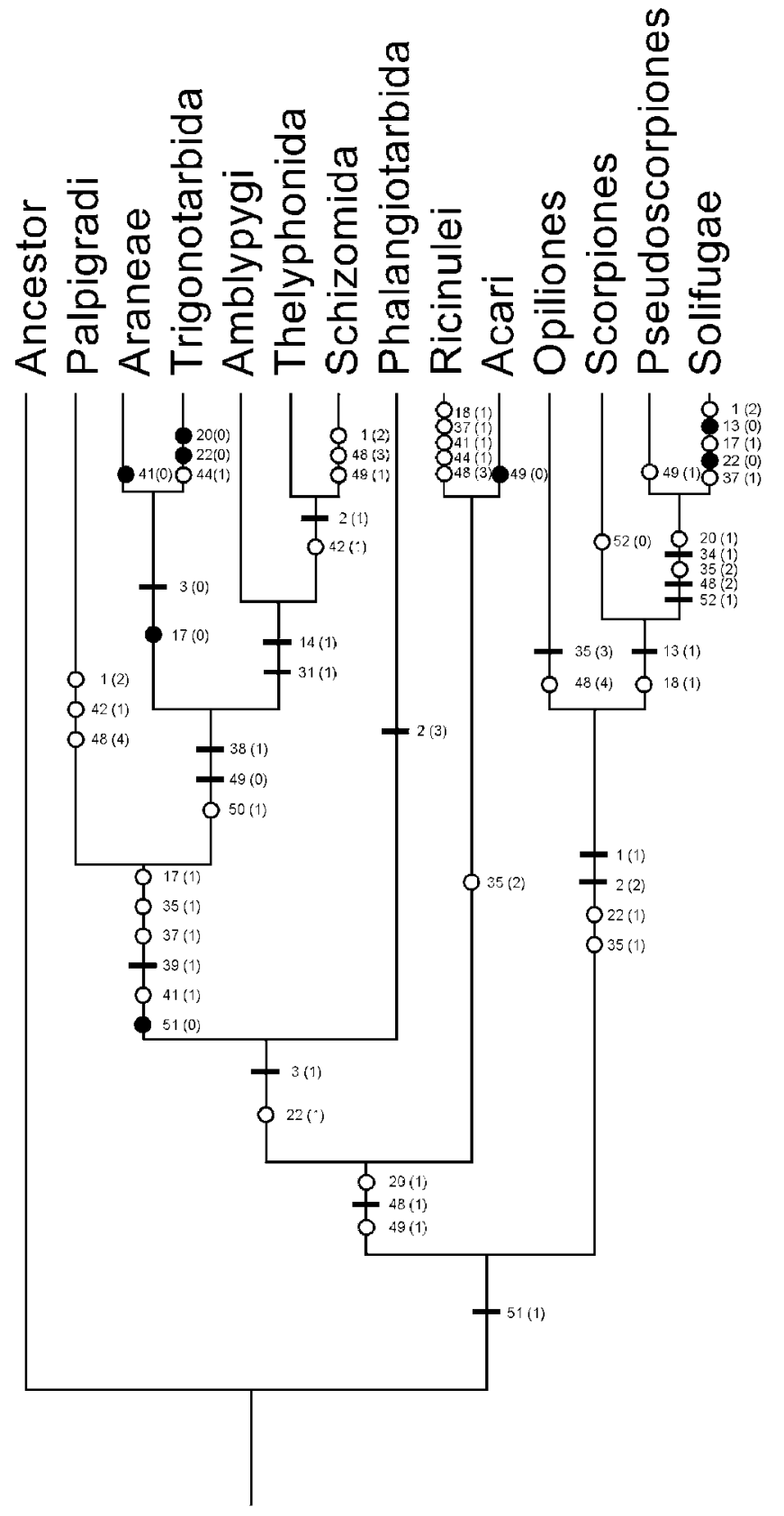

Figure 8 The MPT with the character states fossilisable in Phalangiotarbida mapped on; character states were reconstructed using the 'accelerated transformation optimisation' criterion (ACCTRAN). Each character number corresponds to Section 5.2; the character state change is shown in brackets. Synapomorphies are shown as bars, convergences as open circles and reversals as closed circles.

Legs pediform. Opisthosoma with six abbreviated anterior tergites and four larger posterior tergites, which can be fused or unfused. Opisthosomal sternites longitudinally divided. Anal operculum dorsal (emended from Dunlop \& Horrocks 1997).

Remarks. Rößler \& Schneider (1997) and the present study indicate that not all phalangiotarbids have fused posterior tergites, as suggested previously by Dunlop \& Horrocks (1997). The Chemnitz and Writhlington fossils show that the phalangiotarbid opisthosoma has 10 tergites plus an anal operculum in the groundpattern. The idea that posterior tergites previously described in phalangiotarbids were always the taphonomic effect of sternite segmental lines being superimposed dorsally is unsubstantiated.

Beall (1991) proposed that the terminal position of the anus, which he mentioned for the Writhlington specimens, might be a primitive condition for phalangiotarbids, with '... movement of the anal opening dorsally being an autapomorphy that would define a clade within the order Phalangiotarbida' (Beall 1991, p. 162). Since these specimens were not figured in his paper, this suggestion could not be substantiated here. It seems more likely that the dorsal anal operculum does, in fact, represent another groundpattern character and an autapomorphy that defines the entire Phalangiotarbida clade (see Section 5.4).

Family Architarbidae Karsch, 1882

Emended diagnosis. Phalangiotarbida with the posterior four opisthosomal tergites fused or unfused. All coxae triangular, trochanter comprising a single podomere, legs similar, composed of seven podomeres. Apotele of walking legs trifurcate; all three elements approximately of equal length (emended from Dunlop \& Horrocks 1997).

Included genera. Architarbus Scudder, 1868; Bornatarbus Rößler \& Schneider, 1997; Discotarbus Petrunkevitch, 1913; Geratarbus Scudder, 1890; Goniotarbus Petrunkevitch, 1949; Hadrachne Melander, 1903; Leptotarbus Petrunkevitch, 1945; Mesotarbus Petrunkevitch, 1949; Metatarbus Petrunkevitch, 1913; Ootarbus Petrunkevitch, 1945; Orthotarbus Petrunkevitch, 1945; Paratarbus Petrunkevitch, 1945; Phalangiotarbus Haase, 1890; and Triangulotarbus Patrick, 1989.

Remarks. Dunlop \& Horrocks (1997) diagnosed the family Architarbidae as having 10 opisthosomal tergites. However, whilst true for Phalangiotarbus, Mesotarbus was thought to have only nine by these authors. To resolve this conflict it is proposed here that the diagnosis of Architarbidae should remain as having 10 opisthosomal tergites, and the present authors assume that the fused buckler of Mesotarbus peteri actually represents tergites 7-10, rather than tergites 7-9, as originally suggested by Dunlop \& Horrocks (1997). In general, phalangiotarbids are a fairly homogeneous group whose family-level taxonomy remains equivocal. Preliminary observations suggest that the two remaining, monogeneric, families (Opiliotarbidae and Heterotarbidae) are defined on unreliable characters.

Genus Bornatarbus Rößler \& Schneider, 1997

Diagnosis. Architarbidae with a straight to slightly convex posterior prosoma border. Short tergites 1-6 medially divided, tergites 7-10 separate and not fused together. Dorsal surface exhibiting fine tuberculation. [Translated from Rößler \& Schneider (1997) and, since the genus is monotypic, incorporating their species-specific granulation character].

Type and only species. Bornatarbus mayasii (Haupt in Nindel, 1955).

Remarks. Beall (1991) provisionally assigned various Writhlington fossils to Phalangiotarbus, Leptotarbus and Hadrachne/Goniotarbus. A recent study by Fitton (2002) suggested that the morphological diversity at Writhlington is taphonomic rather than taxonomic in origin. Any difference between the relative length:width ratio of the fossils is thought to be a result of tectonic deformation that has altered many of the Writhlington specimens. Indeed, retro-deformation technique strongly suggests that all the Writhlington phalangiotarbids were conspecific and a clear instar grouping could even be identified (Fitton 2002). Furthermore, these predominantly dorsally preserved fossils are hard to compare directly with Phalangiotarbus, now known only from a ventral neotype. In fact, the Writhlington fossils exactly match the diagnosis of Bornatarbus and, in general form, appear very similar to published photographs of the Chemnitz Basin material. For 
this reason, the present authors assign them to Rößler \& Schneider's (1997) genus.

Some of the Mazon Creek fossils also appear to have medially divided tergites (1-6) and/or unfused tergites (7-10), cf. Geratarbus \& Ootarbus (figures in Petrunkevitch 1955). Thus, the present authors cannot exclude the possibility that an older Mazon Creek genus is a senior synonym of Bornatarbus. Experience has shown that Petrunkevitch's illustrations are often unreliable (see e.g. Selden 1993) and, therefore, the present authors prefer to reserve judgment pending a revision of the Mazon Creek fauna. Unfortunately, Kjellesvig-Waering's posthumous manuscript on the subject was never published.

Bornatarbus mayasii (Haupt in Nindel, 1955)

(Figs 3, 4 a-e, g, h, 5)

Synonymy. See Rößler \& Schneider (1997).

Diagnosis. As for genus.

Type material. Museum für Naturkunde, Berlin (MB.A. 630). Counterpart in the Staatlich Museum für Mineralogie und Geologie, Dresden (SaKa 1).

Additional material. BRSMG, UK, accession numbers Cd5259-98. Phalangiotarbids figured in the present paper are described below.

Description of Cd5262A (counterpart) (Fig. 5a, b) Impression of coxae from walking legs III and IV, a trochanter from leg III and walking leg II of left side preserved. Impression of left side of sternite (S) 2, S3 and S4 preserved. Five posteriormost sternites preserved. Thin strip of cuticle is preserved running up right side of specimen, connecting the carapace to the most posterior sternite. S5 bears a groove that runs parallel with the anterior border and splays out laterally. Slight depressions are seen on S5 and a medial suture from posterior border. Midline lengths of five posteriormost sternites: S5 $1.2 \mathrm{~mm}$, S6 $1.8 \mathrm{~mm}, \mathrm{~S} 72.0 \mathrm{~mm}, \mathrm{~S} 82.0 \mathrm{~mm}, \mathrm{~S} 91.7 \mathrm{~mm}$.

Cd5262B (part) (Fig. 4a-e) External mould of the carapace preserved, showing the carapace grooves and tuberculation. Two huge coxae from walking leg III and IV, a trochanter from leg III, and walking leg II of left side (identity of individual podomeres uncertain). The ventral side is well preserved, showing the five posteriormost sternites. Sternite 5 bears two pairs of ridges interpreted as spiracles (see Section 3.7). These project anteriorly and occur each side of a medial suture that runs from the posterior border of S5 to roughly halfway up S5. This suture terminates in an oval-shaped structure. A deep groove runs anterior to the pairs of putative spiracles. The pairs of ridges are raised on a medial mound that is bordered anteriorly and laterally by a deep groove. The groove traverses the anterior of the median plate of S5 and it splays downwards at each end. Posteriorly and medially to the ridges, there are two slight depressions in the sternite. Midline lengths of posterior five sternites: S5 $1.2 \mathrm{~mm}, \mathrm{~S} 61.8 \mathrm{~mm}, \mathrm{~S} 7$ $2.0 \mathrm{~mm}, \mathrm{~S} 82.0 \mathrm{~mm}, \mathrm{~S} 91.7 \mathrm{~mm}$. A thin strip of cuticle is preserved to the left of the specimen; this joins the carapace to the most posterior sternite.

Cd5266A (Fig. 5f) Only the last five sternites preserved. Vague impression of tenth tergite and anal operculum. Division of posterior sternites into median and lateral plates is clearly seen. Midline lengths of posterior three sternites: S7 $2.3 \mathrm{~mm}$, S8 $2.2 \mathrm{~mm}$, S9 $3.0 \mathrm{~mm}$.

Cd5270A (Fig. 3g, h) Large complete specimen showing dorsal side; no walking legs preserved. Preserved total length $17.8 \mathrm{~mm}$, preserved carapace length $5.5 \mathrm{~mm}$, opisthosoma length $12.3 \mathrm{~mm}$, preserved opisthosoma width $14.6 \mathrm{~mm}$. Broadly rounded anterior border of carapace and posterior end of opisthosoma. Grooves of carapace preserved. Medial ocular tubercle preserved. Two eyes on right side of ocular tubercle preserved. Six abbreviated anterior tergites preserved. Midline lengths: T1 $0.4 \mathrm{~mm}, \mathrm{~T} 20.5 \mathrm{~mm}, \mathrm{~T} 30.5 \mathrm{~mm}, \mathrm{~T} 4$ $0.6 \mathrm{~mm}$, T5 $0.7 \mathrm{~mm}$, T6 $0.8 \mathrm{~mm}$. Four posteriormost tergites preserved. Tergites 7 and 8 wider laterally than medially. Tergites 9 and 10 are reduced in size relative to tergites 7 and 8. Midline lengths: T7 $1.3 \mathrm{~mm}$, T $82.0 \mathrm{~mm}, \mathrm{~T} 91.7 \mathrm{~mm}, \mathrm{~T} 10$ $2.5 \mathrm{~mm}$. The tenth tergite bears an anal operculum (diameter $=$ $1.5 \mathrm{~mm}$ ). Tuberculation present over whole dorsal surface.

Cd5273A (part) (Fig. 5e) and Cd5273B (counterpart) (Fig. 5c). Specimen, without appendages, showing the dorsal side. Carapace not preserved. Anterior tergites and carapace detail unclear. Specimen has been compressed, and shows both the posterior tergal and sternal segmentation. Anal operculum preserved. The apotele, of the walking leg IV on the right-hand side, is visible and measures c. $1 \mathrm{~mm}$ wide and long. Midline length of eight posteriormost tergites: T3 $0.8 \mathrm{~mm}$, T4 $0.8 \mathrm{~mm}$, T5 $1.0 \mathrm{~mm}$, T6 $1.2 \mathrm{~mm}$, T7 $2.3 \mathrm{~mm}$, T8 $2.5 \mathrm{~mm}$, T9 $3.3 \mathrm{~mm}$, T10 $2.7 \mathrm{~mm}$. Midline length of four posteriormost sternites: $\mathrm{S} 6$ $2.2 \mathrm{~mm}, \mathrm{~S} 73.0 \mathrm{~mm}, \mathrm{~S} 82.7 \mathrm{~mm}, \mathrm{~S} 94.7 \mathrm{~mm}$.

Cd5279 (part) (Fig. 3e). Near-complete specimen, without appendages, showing dorsal side. Preserved total length $7.4 \mathrm{~mm}$, preserved carapace length $3.2 \mathrm{~mm}$, opisthosoma length $4.2 \mathrm{~mm}$, preserved opisthosoma width $6.5 \mathrm{~mm}$. Possible juvenile. Ocular tubercle, bearing six eye lenses, is preserved. Longitudinal division of the sternites is detectable.

Cd5282A (part) (Fig. 4g, h). Near-complete specimen, without appendages, showing posterior tergal and sternal segmentation. Preserved total length $16.8 \mathrm{~mm}$, preserved carapace length $5.9 \mathrm{~mm}$, opisthosoma length $10.9 \mathrm{~mm}$, preserved opisthosoma width $6.7 \mathrm{~mm}$. Midline length of tergites: T1 $0.3 \mathrm{~mm}$, T2 $0.5 \mathrm{~mm}, \mathrm{~T} 30.7 \mathrm{~mm}, \mathrm{~T} 40.7 \mathrm{~mm}, \mathrm{~T} 50.7 \mathrm{~mm}, \mathrm{~T} 6$ $0.8 \mathrm{~mm}$, T7 $1.2 \mathrm{~mm}$, T8 $1.8 \mathrm{~mm}$, T9 $2.2 \mathrm{~mm}$, T10 $1.7 \mathrm{~mm}$. Midline length of two posteriormost sternites: $\mathrm{S} 81.7 \mathrm{~mm}$, S9 $3 \cdot 2 \mathrm{~mm}$.

Cd5286A (part) (Fig. 3a, b). Near-complete specimen, without appendages, showing dorsal side. Ocular tubercle, carapace ridges and marginal rim around carapace preserved. Only the first six tergites, and part of the seventh, are preserved. Midline of the anteriormost six tergites: T1 $0.4 \mathrm{~mm}, \mathrm{~T} 2$ $0.6 \mathrm{~mm}$, T3 $0.7 \mathrm{~mm}$, T4 $0.7 \mathrm{~mm}$, T5 $0.8 \mathrm{~mm}$, T6 $1.2 \mathrm{~mm}$.

Cd5287B (counterpart) (Fig. 3c). Internal mould of carapace, showing narrow, pitted marginal rim. Possible walking appendages preserved either side, but these are poorlypreserved and no individual podomeres can be detected.

Cd5300A (part) (Fig. 5g, h). Large complete specimen showing dorsal side; no walking legs preserved. Preserved total length $16.7 \mathrm{~mm}$, preserved carapace length $5.8 \mathrm{~mm}$, opisthosoma length $10.8 \mathrm{~mm}$, preserved opisthosoma width $11.3 \mathrm{~mm}$. Grooves of carapace and medial ocular tubercle, with three pairs of eyes, preserved. Six abbreviated anterior tergites preserved. Midline length of tergites: T1 $0.3 \mathrm{~mm}$, T2 $0.5 \mathrm{~mm}$, T3 $0.5 \mathrm{~mm}$, T4 $0.5 \mathrm{~mm}$, T5 $0.6 \mathrm{~mm}$, T6 $0.8 \mathrm{~mm}, \mathrm{~T} 71.3 \mathrm{~mm}$, T8 $2.0 \mathrm{~mm}$, T9 $1.5 \mathrm{~mm}, \mathrm{~T} 102.0 \mathrm{~mm}$. The tenth tergite bears an anal operculum (diameter $1.2 \mathrm{~mm}$ ). Tuberculation is present over whole dorsal surface.

Cd5302A (counterpart) (Fig. 3d). External mould of three unarticulated coxae.

Remarks. Although the Chemnitz Basin phalangiotarbids come from an older (Viséan) formation than the (Westphalian D) Writhlington site, the present authors can find no clear morphological characters which unequivocally distinguish between the faunas. As noted by Fitton (2002), minor morphological differences (e.g. tagma proportions) in the Writhlington material are unreliable diagnostic characters. The present authors adopt a conservative approach here, given the possibility of undetected synonyms among the Mazon 
Creek fauna; the fossils are assigned to Bornatarbus mayasii as they match its present diagnosis.

\section{Acknowledgements}

Thanks go to R. Clark and P. Stevenson (Bristol Museum and Art Gallery) for allowing access to all phalangiotarbid specimens in their collection. Thanks also go to Dr J. Nudds (Manchester Museum) for the loan of Mesotarbus peteri fossils, Dr P. A. Selden (University of Manchester) for the loans of phalangiotarbid latex peels, and D. Fitton for allowing us to use data from his MSc thesis. Dr R. Rößler (Museum für Naturkunde, Chemnitz) and Dr G. D. Edgecombe (Australian Museum, Sydney) are thanked for providing comments which led to the improvement of the manuscript. Dr R. Rößler is further thanked for providing literature. This work was undertaken by JRP as a part of the MSc in Palaeobiology at the University of Bristol, UK.

\section{References}

Ambrose, T. \& Romano, M. 1972. New Upper Carboniferous Chelicerata (Arthropoda) from Somerset, England. Palaeontology 15, 569-78.

Beall, B. S. 1984. Functional and autecological analyses of phalangiotarbid arachnids. Geological Society of America, Abstracts with Programs 15, 440.

Beall, B. S. 1985. Functional and ecological analyses of phalangiotarbid arachnids (Carboniferous). Masters thesis, University of Michigan.

Beall, B. S. 1991. The Writhlington phalangiotarbids: their palaeobiological significance. Proceedings of the Geologists' Association 102, 161-8.

Beall, B. S. \& Labandeira, C. C. 1990. Macroevolutionary patterns of the Chelicerata and Tracheata. In Culver, S. J. (ed.) Arthropod paleobiology, short courses in paleontology, Vol. 3, 257-87. Knoxville, Tennessee: The Paleontological Society.

Braddy, S. J. \& Dunlop, J. A. 1997. The functional morphology of mating in the Silurian eurypterid, Baltoeurypterus tetragonophthalamus (Fischer, 1839). Zoological Journal of the Linnean Society 121, 435-61.

Bremer, K. 1994. Branch support and tree stability. Cladistics 10, 295-304.

Dunlop, J. A. 1994a. The palaeobiology of the Writhlington trigonotarbid arachnid. Proceedings of the Geologists' Association 105, 287-96.

Dunlop, J. A. 1994b. Filtration mechanisms in the mouthparts of tetrapulmonate arachnids (Trigonotarbida, Araneae, Amblypygi, Uropygi, Schizomida). Bulletin of the British Arachnological Society 9, 267-73.

Dunlop, J. A. 1995. Are the fossil phalangiotarbids just big opilioacarid mites? Newsletter of the British Arachnological Society 74, 8-9.

Dunlop, J. A. 1996a. A trigonotarbid arachnid from the Upper Silurian of Shropshire. Palaeontology 39, 605-14.

Dunlop, J. A. 1996b. Systematics of the fossil arachnids. Revue Suisse de Zoologie hors série, 173-84.

Dunlop, J. A. 1996c. Evidence for a sister group relationship between Ricinulei and Trigonotarbida. Bulletin of the British Arachnological Society 10, 193-204.

Dunlop, J. A. 1997. Palaeozoic arachnids and their significance for arachnid phylogeny. In Zabka, M. (ed.) Proceedings of the $16^{\text {th }}$ European Colloquium of Arachnology, pp. 65-82. Siedlce, Poland.

Dunlop, J. A. 1999. A redescription of the Carboniferous arachnid Plesiosiro madeleyi Pocock, 1911 (Arachnida: Haptopoda). Transactions of the Royal Society of Edinburgh: Earth Sciences 90, 29-47.

Dunlop, J. A. 2002. Character states and evolution of the chelicerate claws. In Toft, S. \& Scharff, N. (eds) Proceedings of the $19^{\text {th }}$ European Colloquium of Arachnology, 345-54. Aarhus: Aarhus University Press.

Dunlop, J. A. \& Braddy, S. J. 2001. Scorpions and their sister-group relationships. In Fet, V. \& Selden, P. A. (eds) Scorpions 2001. In memoriam Gary A. Polis., 1-24. Burnham Beeches: The British Arachnological Society.

Dunlop, J. A. \& Horrocks, C. A. 1996. A new specimen of the Carboniferous trigonotarbid arachnid Maiocercus celticus
(Pocock 1902) from Lancashire, UK. Proceedings of the Yorkshire Geological Society 51, 23-31.

Dunlop, J. A. \& Horrocks, C. A. 1997. Phalangiotarbid arachnids from the Coal Measures of Lancashire. Geological Magazine 134, 369-81.

Faith, D. P. \& Cranston, P. S. 1991. Could a cladogram this short have arisen by chance alone? On permutation tests for cladistic structure. Cladistics 7, 1-28.

Farris, J. S. 1989. The retention index and the rescaled consistency index. Cladistics 5, 417-19.

Felsenstein, J. 1985. Confidence limits on phylogenies: an approach using the bootstrap. Evolution 39, 783-91.

Fitton, D. M. 2002. The Writhlington phalangiotarbids: systematics and ontogeny. Unpublished MSc thesis. University of Bristol.

Fritsch, A. 1904. Palaeozoische Arachniden. Prague: Privately published by Anton Fritsch.

Giribet, G., Edgecombe, G. D., Wheeler, W. C. \& Babbitt, C. 2002. Phylogeny and systematic position of Opiliones: a combined analysis of chelicerate relationships using morphological and molecular data. Cladistics 18, 5-70.

Grasshoff, M. 1978. A model of the evolution of the main chelicerate groups. Symposium of the Zoological Society of London 42, $273-84$.

Haase, E. 1890. Beiträge zur Kenntniss der fossilen Arachniden. Zeitschrift der Deutschen geologischen Gesellschaft 42, 629-57.

Hammen, L. van der 1977. A new classification of the Chelicerata. Zoologische Mededelingen, Leiden 51, 307-19.

Haughton, S. 1877. Description of a fossil spider, Architarbus subovalis, from the Middle Coal Measures, Burnley, Lancashire. Journal of the Royal Geological Society of Ireland 14, 222-3.

Hirst, S. 1923. On some arachnid remains from the Old Red Sandstone (Rhynie Chert Bed, Aberdeenshire). Annals and Magazine of Natural History 9, 455-74.

Jarzembowski, E. A. 1989. Writhlington Geological Nature Reserve. Proceedings of the Geologists' Association 100, 219-34.

Karsch, F. 1882. Über ein neues Spinnenthier aus der Schlesischen Steinkohle und die Arachnoiden der Steinkohlenformation überhaupt. Zeitschrift der Deutschen geologischen Gesellschaft 34, 556-61.

Kitching, I. J., Forey, P. L., Humphries, C. J. \& Williams, D. 1998. Cladistics: the theory and practice of parsimony analysis. Oxford: Oxford University Press.

Kjellesvig-Waering, E. N. 1969. A new phalangiotarbid (Arachnida) from the Pennsylvanian of Oklahoma. Journal of Paleontology 43, $1280-2$.

Kluge, A. G. \& Farris, J. S. 1969. Quantitative phyletics and the evolution of anurans. Systematic Zoology 18, 1-32.

Maddison, W. P. \& Maddison, D. R. 1997. MacClade: analysis of phylogeny and character evolution, Version 3.07. Sunderland, MA: Sinauer.

Melander, A. L. 1903. Some additions to the Carboniferous terrestrial arthropod fauna of Illinois. Journal of Geology 11, 173-98.

Nindel, F. 1955. Die tierische Reste aus dem Karbon von Karl-MarxStadt und Hainichen i. S. Geologie 4, 673-94.

Patrick, R. R. 1989. A new phalangiotarbid (Arachnida) from the Mcleansboro Group (Pennsylvanian) of Indiana. Journal of Paleontology 63, 327-31.

Petrunkevitch, A. I. 1913. A monograph of the terrestrial Palaeozoic Arachnida of North America. Transactions of the Connecticut Academy of Arts and Science 18, 1-137.

Petrunkevitch, A. I. 1945. Palaeozoic Arachnida of Illinois. An enquiry into their evolutionary trends. Illinois State Museum, Scientific Papers 3, 1-72.

Petrunkevitch, A. I. 1949. A study of Palaeozoic Arachnida. Transactions of the Connecticut Academy of Arts and Sciences 37, 69-315.

Petrunkevitch, A. I. 1955. Arachnida. In Moore, R. C. (ed.) Treatise on invertebrate paleontology, Part P, Arthropoda 2, pp. 42-163. Boulder, Colorado \& Lawrence, Kansas: Geological Society of America and University of Kansas Press.

Pinna, M. C. C. de 1991. Concepts and tests of homology in the cladistic paradigm. Cladistics 7, 367-94.

Pocock, R. I. 1910. Notes of the morphology and generic nomenclature of some Carboniferous Arachnida. Geological Magazine 5, $505-12$.

Pocock, R. I. 1911. A monograph of the Terrestrial Carboniferous Arachnida of Great Britain. Monograph of the Palaeontological Society 64, 1-84.

Poschmann, M. \& Jansen, U. 2002. New finds of chelicerate arthropods from the Siegenian (Lower Devonian) of the Rhenish Slate Mountains (Germany). ICP2002, Geological Society of Australia, Abstracts 68, 262-3. 
Rößler, R. \& Schneider, J. W. 1997. Eine bemerkenswerte Paläobiocoenose im Unterkarbon Mitteleuropas-Fossilführung und Paläoenvironment der Hainichen-Subgruppe (ErzgebirgeBecken). Veröffentlichungen des Museums für Naturkunde Chemnitz 20, 5-44.

Rößler, R., Dunlop, J. A. \& Schneider, J. W. 2003. A redescription of some poorly known Rotliegend arachnids from the Lower Permian (Asselian) of the Ilfeld and Saale Basins, Germany. Palaeontologische Zeitschrift 77, 417-27.

Savory, T. H. 1971. Evolution in the Arachnida. Watford: Merrow Monographs.

Scudder, S. H. 1868. Supplement to descriptions of Articulates. Description of fossil insects found on Mazon Creek and near Morris, Grundy Co., Ill. Geological Survey of Illinois 3, 566-72.

Scudder, S. H. 1890. Illustrations of the Carboniferous Arachnida of North America. Memoirs of the Boston Society of Natural History 4, 443-56.

Selden, P. A. 1981. Functional morphology of the prosoma of Baltoeurypterus tetragonophthalmus (Fischer) (Chelicerata; Eurypterida). Transactions of the Royal Society of Edinburgh: Earth Sciences 72, 9-42.

Selden, P. A. 1992. Revision of the fossil ricinuleids. Transactions of the Royal Society of Edinburgh: Earth Sciences 83, 595-634.

Selden, P. A. 1993. Fossil arachnids - recent advances and future prospects. Memoirs of the Queensland Museum 33, 389-400.

Shear, W. A., Selden, P. A., Rolfe, W. D. I., Bonamo, P. M. \& Grierson, J. D. 1987. New terrestrial arachnids from the Devonian of Gilboa, New York (Arachnida, Trigonotarbida). American Museum Novitiates 2901, 1-74.
Shultz, J. W. 1990. Evolutionary morphology and phylogeny of Arachnida. Cladistics 6, 1-38.

Shultz, J. W. 1999. Muscular anatomy of a whipspider, Phrynus longipes (Pocock) (Arachnida: Amblypygi), and its evolutionary significance. Zoological Journal of the Linnean Society 126, 81116.

Smith, A. B. 1994. Systematics and the fossil record: documenting evolutionary patterns. Oxford: Blackwell Science.

Swofford, D. L. 2002. PAUP*. Phylogenetic analysis using parsimony (*and other methods). Version 4.0b10. Sunderland, MA: Sinauer Associates.

Thomas, B. A. \& Cleal, C. J. 1994. Plant fossils from the Writhlington Geological Nature Reserve. Proceedings of the Geologists' Association 105, 15-32.

Todd, J. A. 1991. A forest-litter animal community from the Upper Carboniferous?: notes on the association of animal-body fossils with plants and lithology in the Westphalian D Coal Measures at Writhlington, Avon. Proceedings of the Geologists' Association 102, 179-84.

Wheeler, W. C. \& Hayashi, C. Y. 1998. The phylogeny of the extant chelicerate orders. Cladistics 14, 173-92.

Weygoldt, P. 1998. Evolution and systematics of the Chelicerata. Experimental and Applied Acarology 22, 63-79.

Weygoldt, P. 2000. Whip spiders (Chelicerata: Amblypygi). Their biology, morphology and systematics. Stenstrup: Apollo Books.

Woodward, H. 1872. On a new Arachnide from the Coal-measures of Lancashire. Geological Magazine 9, 385-87.

JESSICA R. POLLITT, Department of Earth Sciences, University of Bristol, Wills Memorial Building, Queen's Road, Bristol, BS8 1RJ, UK.

Current address: Department of Biology and Biochemistry, University of Bath, Bath, BA2 7AY, UK.

e-mail: bspjrp@bath.ac.uk

SIMON J. BRADDY, Department of Earth Sciences, University of Bristol, Wills Memorial Building, Queen's Road, Bristol, BS8 1RJ, UK.

e-mail: s.j.braddy@bristol.ac.uk

JASON A. DUNLOP, Institut für Systematische Zoologie, Museum für Naturkunde der HumboldtUniversität zu Berlin, Invalidenstraße 43, D-10115, Berlin, Germany.

e-mail: jason.dunlop@museum.hu-berlin.de

MS received 21 July 2003. Accepted for publication 7 January 2004. 